\title{
Electrospun -lactalbumin nanofibers for site-specific and fast-onset delivery of nicotine in the oral cavity \\ an in vitro, ex vivo and tissue spatial distribution study
}

Kalouta, Kleopatra; Stie, Mai Bay; Janfelt, Christian; Chronakis, loannis S.; Jacobsen, Jette; Mørck Nielsen, Hanne; Foderà, Vito

Published in:

Molecular Pharmaceutics

Link to article, DOI:

10.1021/acs.molpharmaceut.0c00642

Publication date:

2020

Document Version

Peer reviewed version

Link back to DTU Orbit

Citation (APA):

Kalouta, K., Stie, M. B., Janfelt, C., Chronakis, I. S., Jacobsen, J., Mørck Nielsen, H., \& Foderà, V. (2020). Electrospun -lactalbumin nanofibers for site-specific and fast-onset delivery of nicotine in the oral cavity: an in vitro, ex vivo and tissue spatial distribution study. Molecular Pharmaceutics, 17(11), 4189-4200.

https://doi.org/10.1021/acs.molpharmaceut.0c00642

\section{General rights}

Copyright and moral rights for the publications made accessible in the public portal are retained by the authors and/or other copyright owners and it is a condition of accessing publications that users recognise and abide by the legal requirements associated with these rights.

- Users may download and print one copy of any publication from the public portal for the purpose of private study or research.

- You may not further distribute the material or use it for any profit-making activity or commercial gain

- You may freely distribute the URL identifying the publication in the public portal 


\section{Article}

\section{Electrospun \#-lactalbumin nanofibers for site-specific and fast-onset delivery of nicotine in the oral cavity: an in vitro, ex vivo and tissue spatial distribution study \\ Kleopatra Kalouta, Mai Bay Stie, Christian Janfelt, loannis S. Chronakis, Jette Jacobsen, Hanne Mørck Nielsen, and Vito Foderà}

Mol. Pharmaceutics, Just Accepted Manuscript • DOI: 10.1021/acs.molpharmaceut.0c00642 • Publication Date (Web): 04 Sep 2020

Downloaded from pubs.acs.org on September 6, 2020

\section{Just Accepted}

"Just Accepted" manuscripts have been peer-reviewed and accepted for publication. They are posted online prior to technical editing, formatting for publication and author proofing. The American Chemical Society provides "Just Accepted" as a service to the research community to expedite the dissemination of scientific material as soon as possible after acceptance. "Just Accepted" manuscripts appear in full in PDF format accompanied by an HTML abstract. "Just Accepted" manuscripts have been fully peer reviewed, but should not be considered the official version of record. They are citable by the Digital Object Identifier (DOI®). "Just Accepted" is an optional service offered to authors. Therefore, the "Just Accepted" Web site may not include all articles that will be published in the journal. After a manuscript is technically edited and formatted, it will be removed from the "Just Accepted" Web site and published as an ASAP article. Note that technical editing may introduce minor changes to the manuscript text and/or graphics which could affect content, and all legal disclaimers and ethical guidelines that apply to the journal pertain. ACS cannot be held responsible for errors or consequences arising from the use of information contained in these "Just Accepted" manuscripts. 


\section{Electrospun a-lactalbumin nanofibers for site-specific}

\section{2 and fast-onset delivery of nicotine in the oral cavity: an in}

3 vitro, ex vivo and tissue spatial distribution study

5 Kleopatra Kalouta ${ }^{1, a, b}$, Mai Bay Stie ${ }^{1, a, b}$, Christian Janfelt ${ }^{\mathrm{a}}$, Ioannis S. Chronakis ${ }^{\mathrm{c}}$, Jette Jacobsen ${ }^{\mathrm{a}}$,

6 Hanne Mørck Nielsen*,a,b and Vito Foderà*,a,b

$8{ }^{1}$ Co-first authors: Kleopatra Kalouta, Department of Pharmacy, University of Copenhagen, 9 Universitetsparken 2, 2100 Copenhagen, Denmark \& Mai Bay Stie, Department of Pharmacy, 10 University of Copenhagen, 2 Universitetsparken, 2100 Copenhagen, Denmark

11 * Corresponding authors: Hanne Mørck Nielsen, Department of Pharmacy, University of 12 Copenhagen, 2 Universitetsparken, 2100 Copenhagen, Denmark \& Vito Foderà, Department of 13 Pharmacy, University of Copenhagen, 2 Universitetsparken, 2100 Copenhagen, Denmark

14 a Department of Pharmacy, University of Copenhagen, 2 Universitetsparken, 2100 Copenhagen, 15 Denmark

$16{ }^{\mathrm{b}}$ Center for Biopharmaceuticals and Biobarriers in Drug Delivery, University of Copenhagen, 2 17 Universitetsparken, 2100 Copenhagen, Denmark

18 c DTU Food, Technical University of Denmark, Kemitorvet, B202, 2800 Kgs. Lyngby, Denmark 


\section{ABSTRACT}

20 Nicotine replacement therapy (NRT) formulations for oromucosal administration induce a delayed

21 rise in nicotine blood levels as opposed to the immediate nicotine increase obtained from cigarette 22 smoking; this being a shortcoming of the therapy. Here, we demonstrate that $\alpha$ 23 lactalbumin/polyethylene oxide (ALA/PEO) electrospun nanofibers constitute an efficient 24 oromucosal delivery system for fast-onset nicotine delivery of high relevance for acute dosing NRT 25 applications. In vitro, nicotine-loaded nanofibers showed fast disintegration in water, with a weight 26 loss up to $40 \%$ within minutes, and a faster nicotine release ( $26.1 \pm 4.6 \%$ after 1 min of incubation) 27 of the loaded nicotine compared to two relevant marketed NRT formulations with a comparable 28 nicotine dose (i.e. $7.9 \pm 5.1 \%$ and $2.2 \pm 0.3 \%$ nicotine was released from a lozenge and a sublingual 29 tablet, respectively). Model-fitting of the release data indicated that the release mechanism of 30 nicotine from the hydrophilic nanofibers was possibly governed by more than one type of release 31 phenomena. Remarkably, ex vivo studies using porcine buccal mucosa demonstrated a more 32 efficient permeation of the nicotine released from the nanofibers (flux of $1.06 \pm 0.22$ $33 \mathrm{nmol} /\left(\mathrm{cm}^{2} \times \mathrm{min}\right)$ ) compared to when dosing even a ten-fold concentrated nicotine solution (flux of $\left.34 \quad 0.17 \pm 0.14 \mathrm{nmol} /\left(\mathrm{cm}^{2} \times \min \right)\right)$. Moreover, MALDI MS imaging of ex vivo porcine buccal mucosa 35 exposed to nicotine-loaded nanofibers clearly revealed higher amounts of nicotine throughout the 36 epithelium, as well as in the lamina propria and submucosa of the tissue. Our findings suggest that 37 nicotine-loaded ALA/PEO nanofibers have potential as a mucosal, fast-releasing and 38 biocompatible delivery system for nicotine, which can overcome the limitations of current 39 marketed NRTs.

41 KEYWORDS: Electrospun protein nanofibers; nicotine; nicotine replacement therapy; in vitro 42 characterization; ex vivo tissue permeation; MALDI mass spectrometry imaging 


\section{INTRODUCTION}

44 Tobacco smoking represents a public health issue and is one of the leading yet preventable 45 mortality causes worldwide. ${ }^{1}$ Every year, approximately 6 million deaths globally are attributed to 46 diseases related to cigarette smoking. ${ }^{2}$ Tobacco smoking strains the healthcare system and imposes 47 a great economic burden on society. ${ }^{2}$ The total annual financial cost of smoking, including the 48 productivity losses from death and disability, accounts for more than US \$1.4 trillion, which is 49 equal to a $1.8 \%$ magnitude of the global annual Gross Domestic Product (GDP). ${ }^{2}$ The harmful 50 effects of tobacco smoking on human health are attributed to its toxic components such as carbon 51 monoxide and tar constituents. ${ }^{3}$ However, it is the principal tobacco alkaloid, nicotine, which acts 52 as the neuroactive modulator of the psychopharmacological effects related to the addiction., ${ }^{4,5}$ 53 Nicotine is a small (MW $162.23 \mathrm{~g} / \mathrm{mol})$ diamine $^{6}\left(\mathrm{pKa},{ }_{1} 3.26\right.$ and $\mathrm{pKa}, 27.9$ at $\left.\mathrm{T}=37^{\circ} \mathrm{C}\right){ }^{7}$ which is 54 highly soluble in aqueous media (water solubility between 33 and $100 \mathrm{~g} / \mathrm{L}$ ). ${ }^{8}$

55 Pharmacological and non-pharmacological interventions are recommended strategies for handling 56 tobacco smoking addiction and succeeding in its cessation. ${ }^{9}$ Nicotine replacement therapy and non57 nicotine medication with e.g. bupropion and varenicline are examples of pharmacological 58 approaches, and are recommended as first-line pharmacological treatment. ${ }^{10}$ Non-pharmacological 59 support can be provided by e.g. behavioral counselling. ${ }^{9}$ Noteworthy, it has been shown that the 60 combination of non-nicotine medication and NRT may represent a potential efficient approach. ${ }^{9}$ 61 By replacing the supply of nicotine from tobacco, NRT aids tobacco users in dealing with 62 reinforcing effects induced by cigarette smoking such as cravings and other symptoms, e.g. 63 irritability or sickness caused by nicotine abstinence, ${ }^{11}$ and NRT thus facilitate the transition from 64 cigarette smoking to complete cessation. ${ }^{12,13}$

65 The existing NRT products are generally well tolerated and demonstrate minor adverse effects. ${ }^{14}$ 66 Examples of oromucosally administered NRTs for acute dosing of nicotine comprise nicotine oral 67 spray, chewing gums, oral films, lozenges, and sublingual tablets. ${ }^{15-18}$ The sustained release NRTs, 68 e.g. transdermal patches, mainly act as attenuators of background craving levels due to nicotine 69 abstinence. $^{19}$

70 Nonetheless, numerous challenges are linked to the use of NRTs. Primarily, current NRT 71 formulations that are designed to be administered and absorbed in the oral cavity, do not trigger a 72 physiological response comparable to the response obtained by cigarette smoking and absorption 
73 of nicotine from the respiratory tract. The pharmacokinetics of nicotine upon release and absorption

74 from the current formulations administered in the oral cavity are not as rapid as for nicotine 75 absorbed from cigarettes. ${ }^{3}$ This is due to the fact that the absorption of nicotine into the blood from 76 such products is slower, reaches therapeutic levels later, and that a rapid systemic arterial delivery 77 of nicotine is not achieved. This results in dissatisfaction and further cravings of smokers. ${ }^{3}$ 78 However, nicotine may be sufficiently absorbed into the systemic circulation through the buccal 79 mucosa and examples of NRT formulations targeting this route of administration are e.g. the oral 80 film, ${ }^{20}$ chewing gum ${ }^{21}$ and lozenge. ${ }^{22}$ Unfortunately, significant amounts of nicotine may not be 81 absorbed, but rather swallowed due to saliva flow, followed by extensive first pass metabolism 82 yielding a low bioavailability of nicotine from these products. ${ }^{5,20}$ Swallowed nicotine can 83 eventually also lead to side effects such as gastrointestinal discomfort, nausea, throat soreness, and 84 hiccups. ${ }^{14}$ Moreover, specifically for the gum, nicotine is partially retained and not completely 85 released from the formulation. ${ }^{5}$ There is therefore a need for more fast-acting, effective and user86 friendly NRT formulations, which can satisfy cravings and eventually inhibit smoking relapse to 87 support smokers in coping with smoking cessation. For example, films and wafers with 88 mucoadhesive properties have recently been under investigation as alternative buccal NRT delivery 89 systems. ${ }^{17}$

90 An ideal delivery system for nicotine i) provides ease of self-administration, ii) is intended for e.g. 91 buccal administration, from which site nicotine is efficiently absorbed, iii) disintegrates and 92 facilitates fast nicotine release, and iv) provides a site-specific release of nicotine, thus ensuring a 93 high concentration gradient and enhancing the passive diffusion of nicotine across the mucosa. 94 Nanofibers produced by electrospinning have recently gained ground for numerous applications in 95 areas such as wound healing, tissue engineering, and drug delivery. ${ }^{23}$ This is mainly due to their 96 high drug loading efficiency, tunability, adhesiveness to the site of application, high surface-to97 volume ratio, and ability to control loading and release of molecules at the target site. ${ }^{24}$ Proteins 98 from plant or animal sources are exploited for various biomedical applications due to their 99 structural and functional properties and biocompatibility. ${ }^{25}$ For the current application, nanofibers 100 were produced by waterborne electrospinning of the biocompatible and biodegradable ${ }^{25,26}$ whey 101 protein $\alpha$-lactalbumin (ALA) with minute amounts of polyethylene oxide (PEO), as previously 102 reported. ${ }^{27}$ ALA is heat-stable, digestible, ${ }^{28}$ a natural vehicle of essential micronutrients ${ }^{26}$ and 103 shown to have antibacterial ${ }^{29}$ and anticancer properties. ${ }^{30}$ The protein is a good source of the 
104 essential amino acid tryptophan, which is related to the human ability to cope with stress. ${ }^{31}$ 105 Moreover, ALA-based nanofibers are hydrophilic, scalable and highly tunable, and the protein 106 maintains its native structural characteristics after electrospinning. ${ }^{27}$

107 The objective of the current study was to investigate ALA/PEO nanofibers as a potential NRT 108 formulation for oromucosal administration. Here, we report on ALA/PEO nanofibers loaded with 109 a content of nicotine comparable to that of marketed NRT formulations. The nicotine-loaded 110 nanofibers showed a faster release of nicotine than existing NRTs in vitro. Nicotine released from 111 the nanofibers successfully permeated across filter-grown TR146 cell culture epithelium in vitro 112 and through ex vivo porcine buccal mucosa. Remarkably, the nicotine from the nanofibers 113 penetrated throughout the buccal mucosa and surpassed the epithelial permeability barrier. We 114 demonstrate the potential of ALA/PEO nanofibers as a delivery system for site-specific release of 115 nicotine leading to fast permeation of high amounts of drug. The nanofiber-based delivery system 116 is comparable to marketed NRT formulations in terms of the content of nicotine, but superior in 117 terms of the drug delivery efficiency. 


\section{MATERIALS \& METHODS}

\section{Materials}

120 ALA (92.5\% purity) was kindly provided by Davisco Food International/Agropur Ingredients 121 (Eden Prairie, MN, USA). Nicotine was used in the form of nicotine bitartrate dihydrate (NBT), 122 which was kindly donated by Fertin Pharma A/S (Vejle, Denmark). Nicotinell® $1 \mathrm{mg}$ mint 123 Lozenge (GlaxoSmithKline, Brentford, Middlesex, UK) and NICORETTE® Microtab (McNeil 124 Products, Maidenhead, UK) were purchased through the Association of Danish Pharmacies. PEO 125 (MW 300 kDa), Hanks' Balanced Salt Solution (HBSS), phosphate buffer saline (PBS) pH 7.4, 126 glycerol, sucrose, L-glutamine, penicillin, streptomycin, phenazine methosulfate (PMS), 127 Dulbecco's Modified Eagle's Medium high-glucose (DMEM), 2,5-dihydroxybenzoic acid (DHB), 128 Mayer's hematoxylin solution, alcoholic eosin Y solution, potassium phosphate dibasic, 129 phosphoric acid (85\%), sodium hydroxide, bovine serum albumin (BSA) and the TR146 cell line 130 were purchased from Sigma Aldrich (St. Louis, MO, USA). N-2-hydroxyethylpiperazine-N'-2131 ethanesulfonic acid (HEPES) was obtained from PanRec AppliChem (Damstadt, Germany). Fetal 132 bovine serum (FBS) was obtained from PAA laboratories (Brøndby, Denmark). Acetonitrile 133 (99.9\%) and absolute ethanol (99.97\%) were purchased from VWR Chemicals BDH ${ }^{\circledR}$ International 134 (Leicestershire, UK). 3-(4,5-dimethylthiazol-2-yl)-5-(3-carboxymethoxyphenyl)-2-(4135 sulfophenyl)-2H-tetrazolium) (MTS) was obtained from Promega (Madison, WI, USA). Methanol 136 was purchased from Th. Geyer (Renningen, Germany). Ultrapure water was collected in-house 137 (18.2 M $\Omega \times$ cm by a PURELAB flex 4 system, ELGA, LabWater, High Wycombe, UK).

\section{Methods}

\section{Production of nicotine-loaded ALA/PEO nanofibers}

140 ALA/PEO nanofibers were produced by electrospinning using the method previously described. ${ }^{27}$ 141 Briefly, a $37.5 \%(\mathrm{w} / \mathrm{w})$ solution of ALA in ultrapure water was mixed in a 1:1 (w/w) ratio with a $1427.4 \%(\mathrm{w} / \mathrm{w})$ PEO dispersion in ultrapure water. The mixed dispersion was stirred for at least 30 143 min prior to electrospinning. Subsequently, the dispersion was electrospun at room temperature $144\left(20 \pm 2{ }^{\circ} \mathrm{C}\right)$ with a high voltage supply of 15-16 kV (Gamma High Voltage Research, Ormond 145 Beach, FL, USA), a flow rate of $1 \mathrm{~mL} / \mathrm{h}$ (New Era Pump Systems, Farmingdale, NY, USA), a 146 relative humidity under 30\% (secured by flow of dry air) and a tip-collector distance of $15 \mathrm{~cm}$ from 147 a $5 \mathrm{~mL}$ syringe with a $20 \mathrm{G}$ blunt needle. Assuming total evaporation of the aqueous solvent, 148 nanofibers with a final content of $84 \%(w / w)$ ALA and $16 \%(w / w)$ PEO were produced. The 6 
149 investigated formulation comprised five stacked nanofiber discs cut from the electrospun nanofiber 150 mat by using an aluminum puncher with a diameter of $11 \mathrm{~mm} .15 \mu \mathrm{L}$ of nicotine in absolute ethanol $151(15 \mathrm{mg} / \mathrm{mL})$ was applied on each of the discs dropwise, and the nanofiber discs were layered in the 152 aluminum puncher-container used for cutting (Figure S1, Supporting Information). Slight wetting 153 of the nanofibers by the nicotine in ethanol solution facilitated the adherence of the five discs into 154 one while the ethanol evaporated. The final formulation (nicotine-loaded nanofibers) had a 155 diameter of $11 \mathrm{~mm}$, an average weight of $19.33 \pm 2.89 \mathrm{mg}(\mathrm{N}=3, \mathrm{n}=7$; mean $\pm \mathrm{SD}$, where $\mathrm{N}$ equals 156 the number of different nanofiber mats prepared on different days and $\mathrm{n}$ the number of samples 157 weighed per mat), and carried a theoretical load of $1.125 \mathrm{mg}$ nicotine.

\section{Morphological and in vitro characterization of the nicotine-loaded ALA/PEO nanofibers}

159 Morphological analysis and size evaluation

160 The ALA/PEO nanofibers and the nicotine-loaded nanofibers were morphologically characterized 161 by scanning electron microscopy (SEM). Visualization of the nanofibers was performed under a 162 Phenome Pro X scanning electron microscope (Pheno-World, Eindhoven, Netherlands) at an 163 accelerated voltage of $15 \mathrm{kV}$. The samples were mounted on aluminum SEM stubs with carbon 164 tape and sputter-coated with gold. The diameters of the nanofibers were measured using the 165 IMAGE J software version 1.52h (National Institute of Health, Bethesda, MD, USA) and results 166 were averaged for samples produced on two different days. The diameter of 150-300 individual 167 fibers were measured for each sample. For statistical comparison of the diameters of ALA/PEO 168 nanofibers and nicotine-loaded nanofibers, a two-tailed unpaired t-test with equal variances was 169 employed with prior comparison of variances in the groups by application of statistical analysis by 170 an F-test.

\section{Disintegration study}

172 A disintegration study in water was conducted for nicotine-loaded nanofibers with an average 173 weight of $19.33 \pm 2.89 \mathrm{mg}(\mathrm{N}=3, \mathrm{n}=7$; mean $\pm \mathrm{SD})$. Samples of nicotine-loaded nanofibers were 174 weighed $\left(\mathrm{m}_{\text {initial }}\right)$, placed in $11 \mathrm{~mm}$ aluminum baskets with holes, submerged in $3 \mathrm{~mL}$ ultrapure 175 water, and incubated at $37^{\circ} \mathrm{C}$ for $1 \mathrm{~h}$ with mild agitation $(50 \mathrm{rpm})$ according to previous reports. ${ }^{32}$ 176 Samples were withdrawn at specific time points $(1,5,10,20,30,45$, and $60 \mathrm{~min})$, the containers 177 were gently blotted on paper to remove excess water and the remaining nanofibers were left to dry 
178 until constant weight $\left(\mathrm{m}_{\text {final }}\right)$ was reached. Weight loss was determined by the following equation 179 (Eq. 1):

$$
\text { Weight loss }=\frac{m_{\text {initial }}-m_{\text {final }}}{m_{\text {initial }}} \times 100 \%(\text { Eq. 1) }
$$

182 The results were averaged for samples prepared on three different days, cut out of three different 183 nanofiber mats, prepared on three different days.

\section{Nicotine release profile in vitro}

185 Final formulations of nicotine-loaded nanofibers and non-loaded nanofibers (i.e. fibers treated with 186 an ethanol solution without nicotine) were investigated for release of nicotine. A 2 mg nicotine 187 sublingual tablet, with nicotine in the form of nicotine bound to cyclodextrin (NICORETTE®) 188 Microtab), and a $1 \mathrm{mg}$ nicotine lozenge, with nicotine in the form of NBT salt (Nicotinell® $1 \mathrm{mg}$ 189 mint Lozenge), were used for comparison. The different samples were submerged in $3 \mathrm{~mL} 10 \mathrm{mM}$ HEPES in HBSS (hHBSS) pH 6.8 in a 12-well plate, with all nanofiber samples placed in an aluminum container with holes. Subsequently, the samples were incubated at $37{ }^{\circ} \mathrm{C}$ with mild agitation at $50 \mathrm{rpm} .100 \mu \mathrm{L}$ aliquots of each sample were taken at different time points $(1,5,10$, 20, 30, 45, 60 and $120 \mathrm{~min}$ ), and replaced with $100 \mu \mathrm{L}$ hHBSS $\mathrm{pH}$ 6.8. The aliquots were centrifuged $\left(10,621 \times \mathrm{g}, 8 \mathrm{~min}, 4^{\circ} \mathrm{C}\right)$ and the release of nicotine was quantified by reversed phase high performance liquid chromatography (RP-HPLC) using a prominence system (Shimadzu, Kyoto, Japan) with a C18 $(150 \times 4.6 \mathrm{~mm} ; 5 \mu \mathrm{m})$ column (Phenomenex, Værløse, Denmark) fitted with a security guard cartridge $(4 \times 3 \mathrm{~mm})$ (Phenomenex) and a mobile phase $(15: 85(\mathrm{v} / \mathrm{v}))$ of acetonitrile:dipotassium phosphate $20 \mathrm{mM}$ (pH 8.5; adjusted with phosphoric acid) with a flow rate of $0.8 \mathrm{~mL} / \mathrm{min}$, an injection volume of $10 \mu \mathrm{L}$, and isocratic elution. UV signals were measured with a PDA detector (SPD-M20A-Shimadzu, Kyoto, Japan) at $254 \mathrm{~nm}$. The method was validated using nicotine standards in hHBSS pH 6.8 and nicotine concentrations ranged from $0.4 \times 10^{-3} \mathrm{mg} / \mathrm{mL}$ to

203 Using OriginPro 2019, the initial phase of the release profile (corresponding to approximately 60\% 204 released nicotine) was fitted to three different mathematical drug release models, presented in Table 2051 , where $\mathrm{F}$ is the fraction (\%) of nicotine released in time (min). ${ }^{33,34}$ The Hixson-Crowell model 206 was only used to fit the release data obtained with the lozenge and the sublingual tablet, since it is 
207 only relevant for modeling the release profile of pharmaceutical formulations such as tablets, for 208 which the surface decreases proportionally over time and the geometrical form is maintained. ${ }^{33}$

209 Table 1. Release models fitted to the in vitro nicotine release data for the nicotine-loaded nanofibers, lozenge and 210 sublingual tablet. $F$ is the fraction $(\%)$ of nicotine released over time (min). The Hixson-Crowell model was only used 211 to fit the release data obtained with the lozenge and sublingual tablet.

\begin{tabular}{|c|l|}
\hline \multicolumn{1}{|c|}{ Release model } & \multicolumn{1}{c|}{ Equation } \\
\hline $\begin{array}{c}1^{\text {st }} \text { order } \\
\text { borsmeyer-Peppas for } \\
\text { burstect }\end{array}$ & $\begin{array}{l}\mathrm{F}=100 \cdot\left(1-\mathrm{e}^{-\mathrm{k}_{1} \cdot \mathrm{t}}\right)(\mathrm{Eq} \cdot 2), \mathrm{k}_{1}: 1^{\mathrm{st}} \text { order release constant } \\
\text { min, } \mathrm{F}_{\mathrm{KP}}: \mathrm{k}_{\mathrm{KP}} \cdot \mathrm{t}^{\mathrm{n}}(\mathrm{Eq} \cdot 3), \mathrm{F}_{0}: \text { fraction of nicotine released at } \mathrm{t}=1 \\
\text { exponent, indicating the mechan release constant, n: release }\end{array}$ \\
\hline Hixson-Crowell & $\begin{array}{l}\mathrm{F}=100 \cdot\left[1-\left(1-\mathrm{k}_{\mathrm{HC}}\right)^{3}\right]\left(\text { Eq.4), } \mathrm{k}_{\mathrm{HC}}: \text { Hixson-Crowell release }\right. \\
\text { constant }\end{array}$ \\
\hline
\end{tabular}

212

213 Subsequently, in order to determine the model that fitted best to the release data obtained with each

214 formulation, the Akaike information criterion (AIC) ${ }^{35}$ was applied. AIC was calculated by the 215 following equation (Eq.5):

$$
\text { AIC }=n \times \ln (\text { RSS })+2 \times p(\text { Eq. } 5)
$$

217 , where $\mathrm{n}$ is the number of data points, RSS is the residual sum of squares and $\mathrm{p}$ is the number of 218 parameters in each model. The model with the lowest AIC value was chosen as the best fit.

219 The nicotine release study was performed three times for nanofibers punched out of three different 220 nanofiber mats prepared on three different days. Commercial products (lozenge and sublingual 221 tablet) were from the same batch.

\section{Evaluation of the nanofibers as a drug delivery system to facilitate permeation of nicotine}

223 Nicotine transport across buccal TR146 epithelium and viability of cells

224 The in vitro permeation of nicotine across buccal TR146 epithelium was analyzed as previously 225 described by Nielsen et al..$^{7}$ TR146 cells were cultured in Corning Costar ${ }^{\circledR}$ polystyrene culture 226 flasks $\left(175 \mathrm{~cm}^{2}\right.$, Sigma Aldrich, St. Louis, MO, USA) in DMEM supplemented with FBS (10 $227 \%(\mathrm{v} / \mathrm{v}), \mathrm{L}-\mathrm{glutamine}(2 \mathrm{mM})$, penicillin $(100 \mathrm{U} / \mathrm{mL})$ and streptomycin $(100 \mu \mathrm{g} / \mathrm{mL})$ in a humidified 228 environment at $37{ }^{\circ} \mathrm{C}$ with $5 \% \mathrm{CO}_{2} .4 .3 \times 10^{5}$ TR146 cells were seeded on permeable Falcon ${ }^{\circledR}$ 229 inserts $\left(4.2 \mathrm{~cm}^{2}\right.$, pore size $\left.0.4 \mu \mathrm{m}\right)$ and cultured for 14 days. The cells were initially visualized 
230 under a Leica DM IL LED microscope (Brønshøj, Denmark). The cells were washed twice; each 231 time by adding $750 \mu \mathrm{L}$ and $1.5 \mathrm{~mL}$ warm hHBSS pH 7.4 to the apical and the basal cell side, 232 respectively. Subsequently, the cells were cooled to RT and the initial transepithelial electrical 233 resistance (TEER) was measured using a resistance chamber (Endohm, World Precision 234 Instruments, Sarasota, FL, USA) connected to a voltmeter (EVOM, World Precision Instruments, 235 Sarasota, FL, USA). On the apical side, the cells were either exposed to $750 \mu \mathrm{L}$ hHBSS pH 6.8 236 (control), ALA/PEO nanofibers submerged in $750 \mu \mathrm{L}$ hHBSS pH 6.8, nicotine-loaded ALA/PEO 237 nanofibers submerged in $750 \mu \mathrm{L}$ hHBSS pH 7.4 (end $\mathrm{pH} \sim 6.8$ as the bitartrate decreased the $\mathrm{pH}$ ) 238 or $0.3 \mathrm{mg} / \mathrm{mL}$ nicotine in $750 \mu \mathrm{L}$ hHBSS $\mathrm{pH} 7.4$ (end $\mathrm{pH} \sim 6.8$ as the bitartrate decreased the $\mathrm{pH}$ ). $2390.3 \mathrm{mg} / \mathrm{mL}$ nicotine equals the theoretical concentration of nicotine released from the nanofibers. 240 The inserts were quickly transferred to a new plate with $1.5 \mathrm{~mL} \mathrm{hHBSS} \mathrm{pH} \mathrm{7.4,0.05 \% (w/v)} \mathrm{BSA}$ 241 on the basal side of all inserts to initiate the experiment. The cells were incubated for $3 \mathrm{~h}$ at $37^{\circ} \mathrm{C}$ 242 with mild agitation at $50 \mathrm{rpm}$. Samples of $100 \mu \mathrm{L}$ were withdrawn from the basal side of the inserts 243 at different time points $(15,30,45,60,90,120,150$, and $180 \mathrm{~min})$ and replaced with $100 \mu \mathrm{L}$ of 244 hHBSS pH 7.4, containing $0.05 \%(\mathrm{w} / \mathrm{v})$ BSA. The aliquots were centrifuged $(10,621 \times \mathrm{g}, 8 \mathrm{~min}, 4$ $245{ }^{\circ} \mathrm{C}$ ) and analyzed by RP-HPLC as described in the method for nicotine release. The accumulated 246 amount of nicotine, Q (mmol) transported from the apical to the basal side of the epithelium was 247 determined. $\mathrm{Q} / \mathrm{A}$, where $\mathrm{A}=0.9 \mathrm{~cm}^{2}$ the cross-sectional area of the tissue, was plotted as a function 248 of time ( $\mathrm{min})$. The steady-state flux $\mathrm{J}_{\mathrm{SS}}\left(\mathrm{mol} /\left(\mathrm{cm}^{2} \times \mathrm{s}\right)\right)$ is the slope of the linear part of these curves, 249 and the lag time is the intercept of each of the linear equations with the $\mathrm{x}$-axis. For the nicotine 250 solution, the apparent permeability $\left(\mathrm{P}_{\text {app }}\right)$ for nicotine under sink condition was calculated by the 251 following equation (Eq. 6) utilizing the relevant concentration of nicotine in the test sample $\left(\mathrm{C}_{\text {donor }}\right)$ :

$$
\mathrm{P}_{\mathrm{app}}=\frac{\mathrm{J}}{\mathrm{C}_{\mathrm{donor}}}(\text { Eq. 6) }
$$

253 After $3 \mathrm{~h}$ of incubation, the $\mathrm{pH}$ and osmolality of samples withdrawn from the basal and the apical 254 side of the epithelium were determined. The epithelium was washed twice with hHBSS pH 7.4, 255 cooled to RT and the TEER was measured. The corrected TEER values were calculated by the 256 following equation (Eq. 7):

$$
\text { TEER }=\left(R_{\text {insert with cells }}-R_{\text {insert without cells }}\right) \times A(\text { Eq. 7) }
$$


258 , where $R_{\text {insert with cells }}$ is the resistance of the TR146 epithelium on the inserts and $R_{\text {insert without cells }}$ is 259 the background resistance measurement of the inserts without cells.

260 The viability of the epithelial cells after exposure was evaluated using the MTS/PMS colorimetric 261 assay. The epithelium was again warmed to $37^{\circ} \mathrm{C}$, the buffer was aspirated, $500 \mu \mathrm{L}$ MTS/PMS 262 solution was added to the apical side and $1.5 \mathrm{~mL}$ hHBSS pH 7.4 was added to the basal side. For 263 the MTS/PMS assay, the final concentration of PMS was $1.2 \mu \mathrm{g} / \mathrm{mL}$ and the concentration of MTS 264 was $120 \mu \mathrm{g} / \mathrm{mL}$ in hHBSS pH 7.4. Subsequently, the cells were incubated at $37{ }^{\circ} \mathrm{C}$ with mild 265 agitation at $50 \mathrm{rpm}$ for $40 \mathrm{~min}$ to $1 \mathrm{~h}$. Finally, four aliquots of $80 \mu \mathrm{L}$ were transferred to a transparent 266 96-well plate and the absorbance was measured at $492 \mathrm{~nm}\left(\mathrm{Abs}_{\text {sample }}\right)$ in a plate reader 267 spectrophotometer (POLARstar OPTIMA, BMG LABTECH, Ortenberg, Germany) and the 268 relative cell viability was calculated by the following equation (Eq. 8):

$$
\text { Relative cell viability (\%) }=\frac{\mathrm{Abs}_{\mathrm{sample}}-\mathrm{Abs}_{\mathrm{blank}}}{\mathrm{Abs}_{\mathrm{control}}-\mathrm{Abs}_{\mathrm{blank}}} \times 100 \% \text { (Eq. 8) }
$$

270 , where $\mathrm{Abs}_{\text {blank }}$ is the absorbance of the unreacted MTS/PMS solution at $492 \mathrm{~nm}$ and $\mathrm{Abs}_{\text {control }}$ is 271 the absorbance of the control sample at $492 \mathrm{~nm}$.

272 The transport study was performed on three cell passages for nanofibers punched out of three 273 different nanofiber mats prepared on three different days.

274 Ex vivo permeation of nicotine through porcine buccal mucosa in Ussing chambers

275 The ex vivo permeation study of nicotine through porcine buccal mucosa was analyzed as 276 previously described by Nielsen et al.. ${ }^{7}$ Ex vivo buccal tissue was obtained from healthy 277 experimental Danish Landrace/Yorkshire x Durox (D-LY)) pigs (of approximately $30 \mathrm{~kg}$ ), and 278 stored at $-80{ }^{\circ} \mathrm{C}$ in cryo-medium $(40 \%(\mathrm{w} / \mathrm{v})$ glycerol and $20 \%(\mathrm{w} / \mathrm{v})$ sucrose in PBS $\mathrm{pH} 7.4){ }^{36}$ 279 Initially, the porcine buccal mucosa was gently thawed in PBS in an ice bath with mild agitation 280 to remove the cryo-medium. The mucosal tissue was trimmed with surgical scissors and finally cut 281 with a Stadie-Riggs tissue slider (Thomas Scientific, Swedesboro, NJ, USA) to a thickness of $282759 \pm 104 \mu \mathrm{m}(\mathrm{N}=3, \mathrm{n}=2-3$; mean $\pm \mathrm{SD})$ as determined by a manual micrometer. Then, the buccal 283 mucosa was mounted in Ussing sliders P2413 (Physiologic Instruments, San Diego, CA, USA) 284 with a $0.71 \mathrm{~cm}^{2}$ exposure area. Nicotine-loaded nanofibers were placed on the buccal mucosa and 285 fixed in place with Parafilm to ensure unidirectional release. The sliders were secured in Ussing 
286 chambers (Physiologic Instruments, San Diego, CA, USA), with the epithelium facing the donor 287 chamber. $2.0 \mathrm{~mL}$ PBS with $0.05 \%(\mathrm{w} / \mathrm{v})$ BSA was added in the receptor chamber. $2.0 \mathrm{~mL}$ of 5.625 $288 \mathrm{mg} / \mathrm{mL}$ nicotine in PBS (pH 3.28 due to the influence of tartaric acid) was added on the donor side 289 of the chambers without nanofibers (control samples). $5.625 \mathrm{mg} / \mathrm{mL}$ nicotine is equal to $10 \times$ the 290 theoretical concentration of nicotine released from the nanofibers. Samples of $100 \mu \mathrm{L}$ were taken 291 from the receptor chamber at different time points $(1,15,30,45,60,90,120,150,180,210,240$, 292 270, and $300 \mathrm{~min})$ and replaced with equal amounts of PBS containing $0.05 \%(\mathrm{w} / \mathrm{v})$ BSA. Donor 293 samples were taken from the control samples at the beginning and at the end of the experiment. 294 The samples were centrifuged $\left(10,621 \times \mathrm{g}, 8 \mathrm{~min}, 4{ }^{\circ} \mathrm{C}\right)$ and analyzed by the RP-HPLC method 295 described above. Flux values for each of the samples and permeability for the nicotine solution 296 were calculated using the method described in the transport study. Throughout the experiment, the 297 temperature was kept at $37 \pm 2{ }^{\circ} \mathrm{C}$ and hydrated atmospheric air was supplied for stirring. The $e x$ 298 vivo study was performed three times on tissue obtained from three individual pigs. Six nicotine299 loaded nanofibers samples from three different nanofiber mats were used.

300 MALDI mass spectrometry (MS) imaging and hematoxylin and eosin (H\&E) staining with

301 visualization by microscopy

302 For MALDI MS imaging, ex vivo porcine buccal mucosa was trimmed using surgical scissors to 303 an approximate thickness of $3 \mathrm{~mm}$, and placed in an Ussing chamber slider (area $0.71 \mathrm{~cm}^{2} ; \mathrm{P} 2413$; 304 Physiologic Instruments, San Diego, CA, USA) with the nicotine-loaded ALA/PEO nanofibers and 305 Parafilm as described in the ex vivo methods section above. The porcine buccal mucosa was 306 exposed to the nicotine-loaded nanofibers under the same conditions as used for the ex vivo 307 experiment above, but the experiment was terminated after $1 \mathrm{~h}$ of incubation. At the end of the 308 incubation, the nanofibers were gently removed from the buccal tissue, and the tissue was placed 309 in aluminum foil at $-80^{\circ} \mathrm{C}$. Cryo-sectioning, matrix application and MALDI MS imaging were 310 performed using the method described by Marxen et al.. ${ }^{8}$ Briefly for imaging, as previously 311 described, ${ }^{8}$ the analysis was performed on a Thermo QExactive Orbitrap mass spectrometer 312 (Thermo Fisher Scientific, Bremen, Germany) equipped with the AP-SMALDI10 Ion source 313 (TransMIT Gesellschaft für Technologietransfer, Gießen, Germany) with a mass range of $\mathrm{m} / \mathrm{z}$ 314 150-800 in positive ionization mode. The mass resolving power was $140,000 @ \mathrm{~m} / \mathrm{z} 200$ and the $315 \mathrm{~m} / \mathrm{z} 295.02131$ signal of the DHB matrix was used as a lock mass to ensure a mass accuracy of 2 12 
316 ppm. Images with a pixel size of $20 \mu \mathrm{m}$ were acquired. Raw data were converted to imzML files 317 and visualized in MSiReader software version $0.09^{37}$ (5 ppm bin width). Subsequently, $96 \%(\mathrm{v} / \mathrm{v})$ 318 ethanol was used to wash off the matrix from the tissue section, which was then stained with 319 hematoxylin and eosin (H\&E) as described by Janfelt et al. ${ }^{38}$ and imaged under a light microscope 320 (Olympus, Tokyo, Japan) equipped with the AxioCam ERc5s camera (Zeiss, Jena, Germany). The 321 experiment was performed twice for nanofibers punched from two different nanofiber mats 322 prepared on two different days and on ex vivo buccal tissue from two individual pigs. 


\section{RESULTS \& DISCUSSION}

\section{Morphology of nicotine-loaded ALA/PEO nanofibers}

325 Unique characteristics of electrospun nanofibers such as high drug loading capacity and large 326 surface area ${ }^{39}$ have previously motivated electrospinning of the whey protein ALA into uniform, 327 beadless nanofibers for drug delivery applications. ${ }^{27}$ Properties of ALA, such as stability, 328 biocompatibility and, most importantly, its high water solubility across a wide $\mathrm{pH}$ range ${ }^{28}$ raised 329 the hypothesis that depositing nicotine on electrospun ALA/PEO nanofibers could result in a 330 promising fast onset nicotine delivery system for buccal administration. In accordance with 331 previously obtained results, ${ }^{27}$ ALA/PEO nanofibers demonstrated an average diameter of $646 \pm 110$ $332 \mathrm{~nm}(\mathrm{~N}=2, \mathrm{n}=300$; mean \pm standard deviation (SD)). Nicotine was deposited onto the ALA/PEO 333 nanofibers via a 5-layer method in an amount comparable to marketed NRT formulations $(1.125$ $334 \mathrm{mg}$ nicotine) (Figure S1). The nicotine-loaded ALA/PEO nanofibers appeared less flexible and 335 more fragile than the neat ALA/PEO nanofibers after visual examination (Figures 1A/top-left and 336 1B/top-left), but not to an extent that limited handling. Nicotine-loaded nanofibers maintained a 337 fibrous, entangled structure after deposition of nicotine (Figure 1B/top-right). The average 338 diameter of the nicotine-loaded nanofibers $(692 \pm 134 \mathrm{~nm})(\mathrm{N}=2, \mathrm{n}=150$; mean $\pm \mathrm{SD})$ (Figure $3391 \mathrm{~B} /$ bottom) was significantly higher $(\mathrm{p}<0.0001)$ than the diameter of the neat ALA/PEO nanofibers $340(646 \pm 110 \mathrm{~nm})(\mathrm{N}=2, \mathrm{n}=300$; mean $\pm \mathrm{SD})$ (Figure 1A/bottom). This could be explained by swelling 341 of the nanofibers after exposure to the ethanol solution. 
(A)
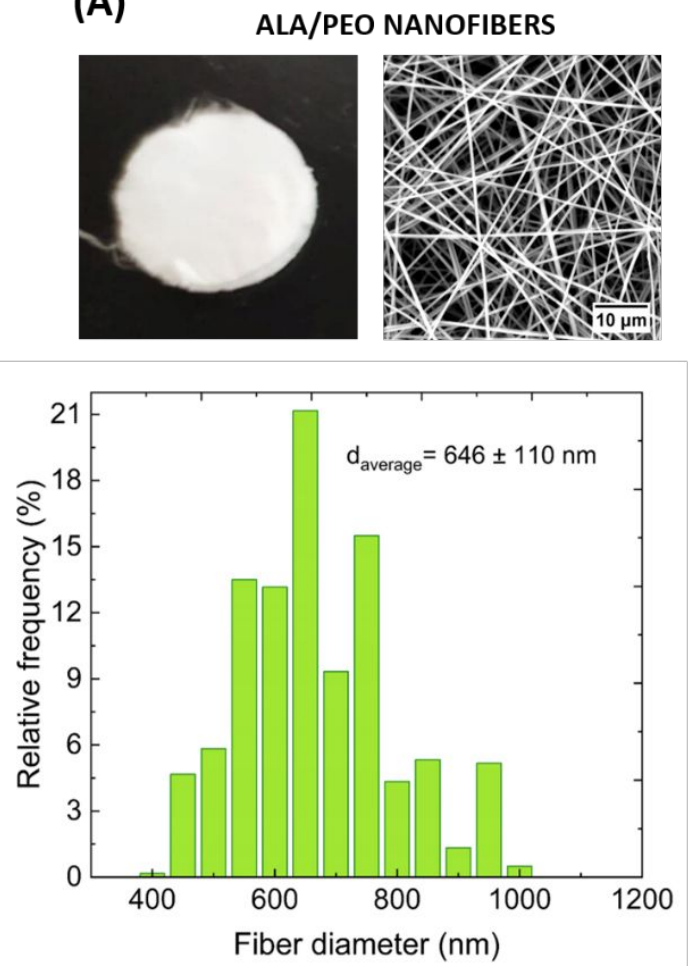

(B)
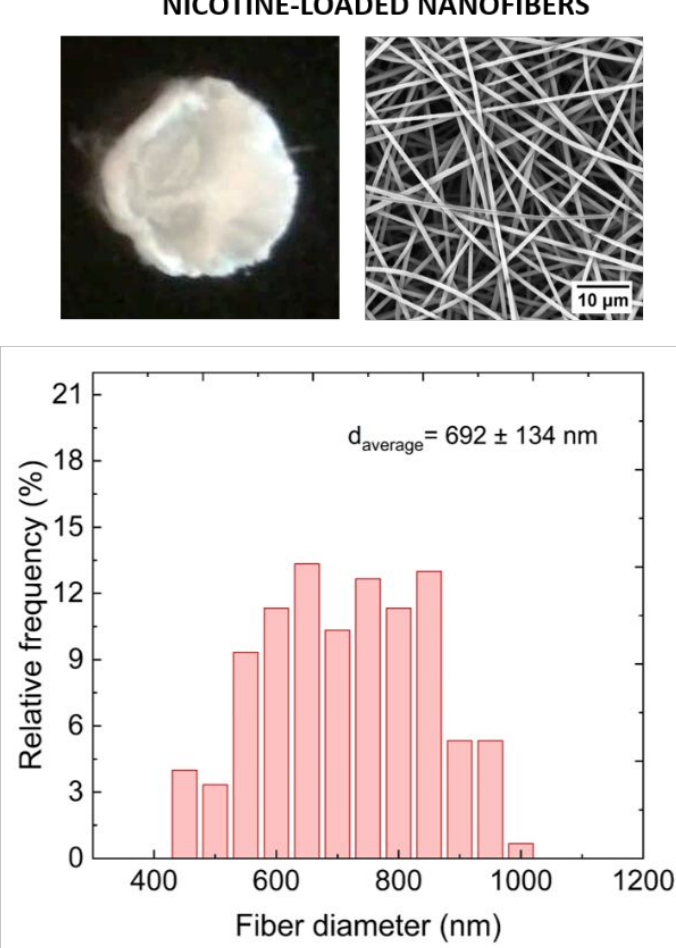

342

343

344

345

346

347

348

349

350

351

352

353

354

355

356

357

358

359

Figure 1. Characterization of nicotine-loaded nanofibers. (A) Disc of neat ALA/PEO nanofibers with a diameter of $11 \mathrm{~mm}$ (top-left), representative SEM image of the samples (top-right) and relative frequency (\%) of the diameters of nanofibers (bottom). (B) Disc of nicotine-loaded ALA/PEO nanofibers with a diameter of $11 \mathrm{~mm}$ (top-left), representative SEM image of the sample (top-right) and relative frequency (\%) of the diameters of nicotine-loaded nanofibers (bottom). $\mathrm{N}=2, \mathrm{n}=150-300, \mathrm{~N}$ representing the number of nanofiber mats prepared on separate days and $n$ the number of measured diameters per sample.

\section{Nicotine-loaded nanofibers disintegrated quickly in aqueous media}

The disintegration of nicotine-loaded ALA/PEO nanofibers in water was further evaluated and, as expected, a significant weight loss was detected for the nanofibers upon exposure to water (Figure 2). In accordance with previous findings, the hydrophilicity of ALA and PEO led to instant disintegration of the ALA/PEO nanofibers upon exposure to an aqueous medium. ${ }^{27}$ Nicotineloaded ALA/PEO nanofibers also demonstrated a rapid disintegration with up to $40 \%$ weight loss within minutes and only remnants of nanofibers observed by the end of the study. In total, a loss of more than $80 \%$ of their initial weight was observed within $1 \mathrm{~h}$ (Figure 2). This confirms that the intrinsic hydrophilic nature of the components of the nicotine-loaded nanofibers (ALA, PEO and nicotine) was maintained. ${ }^{6,28}$ Interestingly, the nicotine-loaded nanofibers did not fully disintegrate after $1 \mathrm{~h}$, probably due to the acidic environment created by the tartaric acid salt of $\mathrm{NBT},{ }^{40}$ which could have altered the disintegration properties of the nanofibers in aqueous medium. The buffer 
360 hHBSS pH 6.8 (salivary $\mathrm{pH})^{41}$ is more physiologically relevant than water in maintaining $\mathrm{pH}$ and

361 being isoosmolal. However, for practical reasons water was chosen as the disintegration medium 362 to avoid the additional weight due to deposition of salts from the buffer on the nanofibers after 363 drying.

364 In general, electrospun hydrophilic nanofibers have been investigated as potential drug delivery 365 systems for rapid release of deposited drugs. ${ }^{42}$ Designed to be instantly wetted by saliva, they 366 disintegrate fast, directly release and deliver the loaded drug into e.g. the buccal mucosa for 367 immediate systemic absorption. ${ }^{42}$ For instance, a study conducted on polyvinyl pyrrolidone (PVP) 368 electrospun nanofibers loaded with the non-steroidal anti-inflammatory drug ketoprofen indicated 369 that hydrophilic nanofibers display higher drug loading and faster drug release as opposed to that 370 observed from hydrophobic nanofibers based on ethyl cellulose and cellulose acetate. ${ }^{43}$

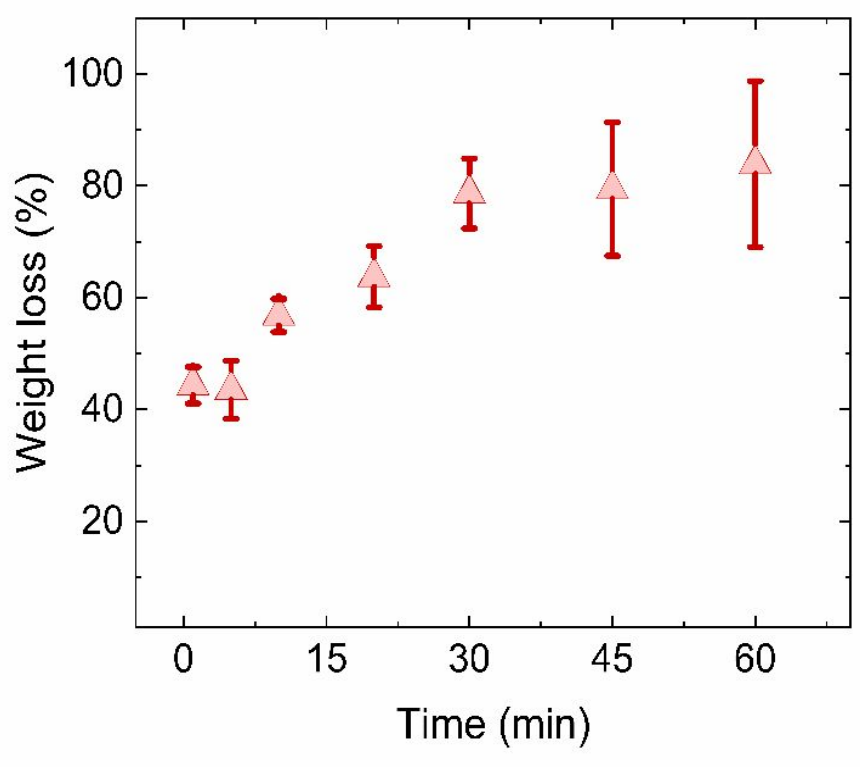

371

372 Figure 2. Disintegration of nicotine-loaded nanofibers of an average weight of $19.33 \pm 2.89 \mathrm{mg}$ in $3 \mathrm{~mL}$ ultrapure water. $\mathrm{N}=3$,

$373 \mathrm{~N}$ representing the number of different nanofiber mats prepared on different days. Results presented as the mean \pm SD.

374 Nicotine-loaded nanofibers demonstrated a more rapid and efficient release profile 375 compared to two marketed NRTs

376 The in vitro release profile of nicotine from the nanofibers was compared to the release profile of 377 two marketed NRTs for oromucosal administration: a sublingual tablet and a lozenge. The 378 sublingual tablet and the lozenge were chosen as these are acute dosing NRTs for rapid nicotine 379 release and are for administration in the oral cavity. Via our deposition method, the nicotine-loaded 16 
380 nanofibers had a nicotine content comparable to these marketed NRTs. Figure 3 represents the 381 cumulative release of nicotine in percent of the total loaded amount of nicotine in the three 382 formulations evaluated $(1.125 \mathrm{mg}, 1 \mathrm{mg}$, or $2 \mathrm{mg}$ in the nanofibers, the lozenge, or the sublingual 383 tablet, respectively). The release study was conducted for $2 \mathrm{hrs}$ to investigate the complete release 384 of nicotine from the nanofibers. $94.3 \pm 5.9 \%(\mathrm{~N}=3$, mean $\pm \mathrm{SD})$ of the nicotine deposited on the $385 \mathrm{ALA} / \mathrm{PEO}$ nanofibers was released within $2 \mathrm{~h}$ of incubation. A faster rate of nicotine release is 386 observed for the nicotine-loaded nanofibers compared to that of the marketed formulations (Figure 387 3, highest rate constant in Table 2). Already after 1 min of incubation, $26.1 \pm 4.6 \%(\mathrm{~N}=3$; mean \pm $388 \mathrm{SD})$ of the loaded nicotine was released from the nanofibers as opposed to only $7.9 \pm 5.1 \%(\mathrm{~N}=3$; 389 mean $\pm \mathrm{SD})$ and $2.2 \pm 0.3 \%(\mathrm{~N}=3$; mean $\pm \mathrm{SD})$ nicotine released from the lozenge and the sublingual 390 tablet, respectively. After $1 \mathrm{~h}, 89.1 \pm 5.9 \%(\mathrm{~N}=3$; mean $\pm \mathrm{SD})$ of the loaded nicotine was released 391 from the nanofibers, while $32.5 \pm 8.5 \%(\mathrm{~N}=3$; mean $\pm \mathrm{SD})$ and $77.0 \pm 19.7 \%(\mathrm{~N}=3$; mean $\pm \mathrm{SD})$ of 392 the loaded nicotine was released from the lozenge and the sublingual tablet, respectively.

393 Most of the nicotine loaded onto the nanofibers was expected to be at or near the surface of the 394 nanofibers, which could explain the faster release of nicotine. Also, with the deposition method 395 used for this formulation, nicotine was expected to be weakly associated to the drug delivery system 396 or adsorbed on its large surface area and thus display a rapid release. ${ }^{44}$ Accordingly, previous 397 studies on an oral fast-dissolving nanofibrous delivery system of caffeine and riboflavin showed 398 that the molecular characteristics, the dispersed state and the solubility of the incorporated drugs 399 in the formulation significantly influenced the release of the drugs. ${ }^{45}$ In contrast, probably due to 400 differences in the excipients and type of formulation (e.g. cyclodextrin bound nicotine in the 401 sublingual tablet), the sublingual tablet and lozenge showed a slower release rate of nicotine in 402 comparison to the nanofibers. ${ }^{44}$ In accordance with the obtained results, previous release tests on 403 patented and marketed lozenges with a USP dissolution Apparatus 1 at $100 \mathrm{rpm}$ in phosphate buffer $404 \mathrm{pH} 7.5$ claimed no more than $50 \%$ release of nicotine after $1 \mathrm{~h}$ of dissolution test. ${ }^{46}$ The slow release 405 of nicotine from the lozenge could partially be explained by the fact that the in vivo suction action 406 was not simulated sufficiently in the current experimental setup. As also stated by a previous study 407 on nicotine release from chewing gums, the evaluation of the performance requires suitable 408 chewing apparatus to simulate the masticatory action. ${ }^{47}$ Noteworthy, in contrast with other NRT 409 formulations, the nanofibers were designed to be wetted by saliva, disintegrate and release nicotine 
410 instantaneously towards the buccal mucosa by being easily administered i.e. without requiring 411 efforts of the user such as chewing or suction.

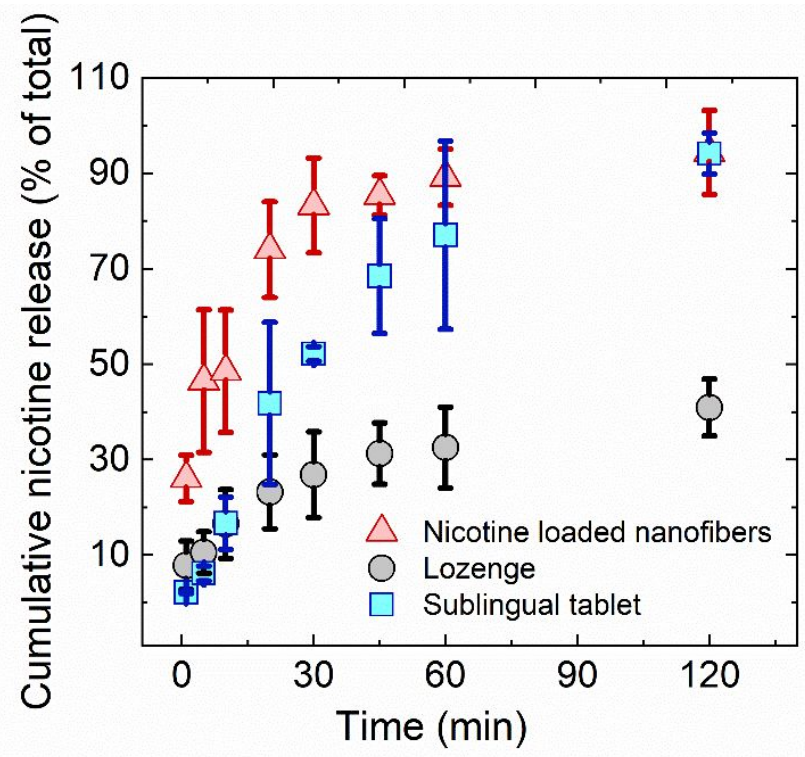

412

413 Figure 3. In vitro release profile of nicotine from nicotine-loaded nanofibers (1.125 mg nicotine), lozenge (1 mg nicotine) 414 415 416

and sublingual tablet ( $2 \mathrm{mg}$ nicotine). The cumulative amount of released nicotine calculated relative to the total amount of loaded nicotine of each formulation as a function of time. $\mathrm{N}=3, \mathrm{~N}$ representing the number of nanofiber mats prepared on different days, presented as the mean $\pm \mathrm{SD}$.

To further investigate the release of nicotine from the three types of formulations, the release data were fitted to three mathematical drug release models: the $1^{\text {st }}$ order kinetics model (Figure S2A, Supplementary Information), the Korsmeyer-Peppas model for the case of a burst initial release effect (Figure S2B, Supplementary Information) and the Hixson-Crowell model (Figure S2C, Supplementary Information). ${ }^{33,34}$ The kinetic parameters, the $\mathrm{R}^{2}$ values and the AIC values obtained from fitting the data to the three models and application of (Eq. 5) are presented in Table 2. $\mathrm{R}^{2}$ values were high $\left(\mathrm{R}^{2} \geq 0.962\right)$ for all, except for the release data obtained with the sublingual tablet when fitted to the Korsmeyer-Peppas model for burst effect $\left(R^{2}=0.753\right)$. $R^{2}$ values $\left(R^{2} \geq 0.962\right)$ indicated a good fit of the release data obtained with the different formulations to the respective models. When fitting the data to the Korsmeyer-Peppas model for burst effect, the release exponent (n) values obtained were $0.732,0.860$ and 1.000 for the nicotine-loaded nanofibers, lozenge and sublingual tablet, respectively. The value of $n=1.000$, obtained for the sublingual tablet is considered unreliable, due to the low $\mathrm{R}^{2}$ value obtained for the respective data set $\left(\mathrm{R}^{2}=0.753\right)$. The obtained release constant values for data fitted to the Korsmeyer-Peppas model 
431 for burst nicotine release $(\mathrm{n} \geq 0.73$ ) from the nanofibers and from the lozenge indicated a non432 Fickian and anomalous diffusion. This implies a release mechanism governed by more than one 433 type of release phenomena; for example diffusion and swelling, or diffusion and erosion. ${ }^{33,35}$ The $4341^{\text {st }}$ order release rate constant $\left(k_{1}\right)$ and the Korsmeyer-Peppas rate constant $\left(k_{K P}\right)$ were higher for 435 the nicotine-loaded nanofibers than for the lozenge and the sublingual tablet. Application of the 436 AIC demonstrated that the release data of the nicotine-loaded nanofibers fitted best to the $1^{\text {st }}$ order 437 kinetics model, whereas the release data of the lozenge and the sublingual tablet fitted best to the 438 Hixson-Crowell release model. Furthermore, release data of the nicotine-loaded nanofibers was 439 best fitted by the $1^{\text {st }}$ order kinetics model, which is applicable for soluble drugs incorporated in a 440 porous matrix and furthermore indicates that the amount of nicotine released remains proportional 441 to the amount of nicotine remaining in the polymeric, porous matrix. ${ }^{35}$ In contrast, the release of 442 nicotine from the lozenge and the sublingual tablet was best fitted by the Hixson-Crowell release 443 model, which suggests that the release from these two formulations is driven by diffusion with a 444 minor effect of matrix dissolution/erosion. ${ }^{33,48}$

445 Table 2: Kinetic parameters, $\mathbf{R}^{2}$ and AIC values obtained from fitting the $\mathbf{1}^{\text {st }}$ order kinetics, the Korsmeyer-Peppas 446 model for burst effect and the Hixson-Crowell model to $60 \%$ of the obtained in vitro nicotine release data of the 447 formulations tested: nicotine-loaded nanofibers, lozenge and sublingual tablet. The Hixson-Crowell model was only 448 fitted to the release data of the lozenge and the sublingual tablet.

\begin{tabular}{|c|c|c|c|c|c|c|}
\hline Formulation $\backslash$ Release model & & letics & & $\begin{array}{l}\text { eppas } \\
\text { fect }\end{array}$ & & well \\
\hline \multirow{4}{*}{ Nicotine-loaded nanofibers } & \multirow{2}{*}{$\mathrm{k}_{1}$} & \multirow{2}{*}{0.063} & $\mathrm{k}_{\mathrm{KP}}$ & 4.903 & \\
\hline & & & $\mathrm{n}$ & 0.732 & & \\
\hline & $\mathrm{R}^{2}$ & 0.980 & $\mathrm{R}^{2}$ & 0.962 & & - \\
\hline & AIC & -8.795 & AIC & 25.902 & & - \\
\hline \multirow{4}{*}{ Lozenge } & $\mathrm{k}_{1}$ & 0.012 & $\mathrm{k}_{\mathrm{KP}}$ & 1.065 & \multirow{2}{*}{$\mathrm{k}_{\mathrm{HC}}$} & \multirow{2}{*}{0.004} \\
\hline & & & $\mathrm{n}$ & 0.860 & & \\
\hline & $\mathrm{R}^{2}$ & 0.936 & $\mathrm{R}^{2}$ & 0.973 & $\mathrm{R}^{2}$ & 0.999 \\
\hline & AIC & -19.319 & AIC & 13.801 & AIC & -30.315 \\
\hline \multirow{4}{*}{ Sublingual tablet } & $\mathrm{k}_{1}$ & 0.025 & $\mathrm{k}_{\mathrm{KP}}$ & 1.176 & \multirow{2}{*}{$\mathrm{k}_{\mathrm{HC}}$} & \multirow{2}{*}{0.007} \\
\hline & & & $\mathrm{n}$ & 1.000 & & \\
\hline & $\mathrm{R}^{2}$ & 0.989 & $\mathrm{R}^{2}$ & 0.753 & $\mathrm{R}^{2}$ & 0.999 \\
\hline & AIC & -21.036 & AIC & 34.900 & AIC & -33.781 \\
\hline
\end{tabular}


450 Nicotine released from biocompatible nanofibers was transported across the buccal TR146 451 cell culture epithelium

452 The nanofibers were evaluated as a drug delivery system to facilitate the release and permeation of 453 nicotine across the buccal epithelial barrier as demonstrated by a transport study using the human 454 buccal epithelial TR146 cell culture model (Figure 4). The pH of the cell buffer was adjusted to a 455 physiologically relevant $\mathrm{pH}$ of 6.8 (the average $\mathrm{pH}$ of saliva $)^{41}$ to counteract the decrease in $\mathrm{pH}$ 456 induced by the bitartrate salt of NBT and potential undesired related effects on cell viability and 457 epithelial integrity. Furthermore, controlling the $\mathrm{pH}$ was crucial as the permeation of nicotine 458 depends on the degree of molecular ionization and thus $\mathrm{pH} .^{7}$

459 Neither the neat ALA/PEO nanofibers, the nicotine-loaded ALA/PEO nanofibers, nor nicotine in 460 solution $(0.3 \mathrm{mg} / \mathrm{mL}$-corresponding to the theoretical concentration of nicotine released from a 461 nicotine-loaded nanofiber disc) affected the viability of the TR146 cells compared to the buffer 462 control (Figure 4A). Thus, good biocompatibility of the proposed drug delivery system was hereby 463 demonstrated.

$4649.6 \pm 1.6 \%(\mathrm{~N}=3, \mathrm{n}=3$; mean $\pm \mathrm{SD})$ and $7.2 \pm 1.2 \%(\mathrm{~N}=3, \mathrm{n}=2-3$; mean $\pm \mathrm{SD})$ of the nicotine in 465 solution and the nicotine in the nanofibers, respectively, was transported from the apical to the 466 basal side of the TR146 cell layers within $3 \mathrm{~h}$ (Figure 4B). No notable difference was detected 467 between the flux values of nicotine in solution with a concentration of $0.3 \mathrm{mg} / \mathrm{mL}$ and nicotine 468 released from a nicotine-loaded ALA/PEO nanofiber disc; which were $0.73 \pm 0.17 \mathrm{nmol} /\left(\mathrm{cm}^{2} \times \min \right)$ $469(\mathrm{~N}=3, \mathrm{n}=3$; mean $\pm \mathrm{SD})$ and $0.6 \pm 0.11 \mathrm{nmol} /\left(\mathrm{cm}^{2} \times \min \right)(\mathrm{N}=3, \mathrm{n}=2-3$; mean $\pm \mathrm{SD})$, respectively. 470 This indicated that the permeability barrier was intact and not compromised by the presence of the 471 nanofibers. The apparent permeability of the nicotine in solution was $6.6 \pm 1.6 \times 10^{-6} \mathrm{~cm} / \mathrm{s}(\mathrm{N}=3$, $472 \mathrm{n}=3$; mean $\pm \mathrm{SD}$ ), which is in line with previously reported studies of nicotine permeation across 473 the TR146 cell culture epithelium $\left(\mathrm{P}_{\mathrm{app}}=8.3 \pm 1.5 \times 10^{-6} \mathrm{~cm} / \mathrm{s}\right) .{ }^{49}$ All samples applied to the cell 474 culture model were isoosmolal $(\sim 300 \mathrm{mOsmol} / \mathrm{kg})$. No notable differences were detected in the 475 TEER before and after incubation, and the TEER were in the range $39-50 \Omega \times \mathrm{cm}^{2}$ for all samples 476 evaluated. Hence, the epithelial integrity was maintained throughout the transport study. 
(A)

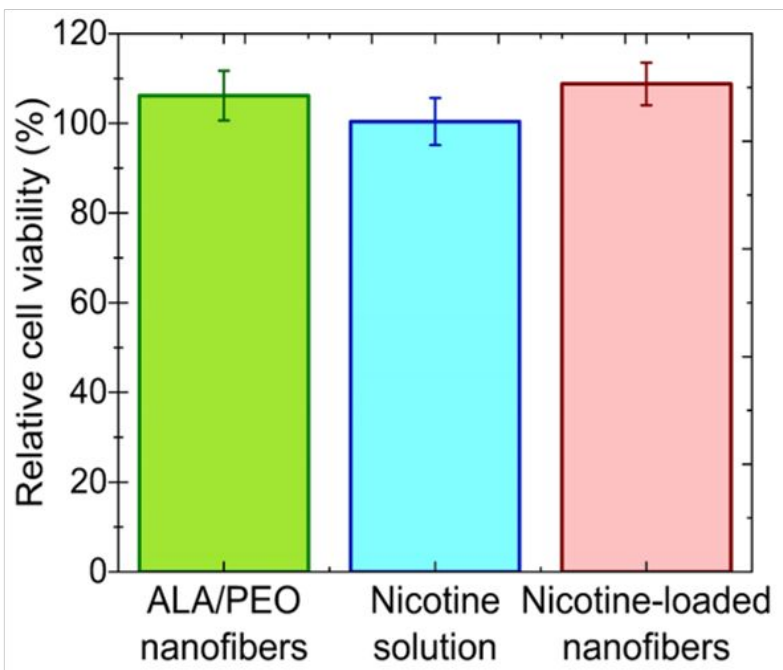

(B)

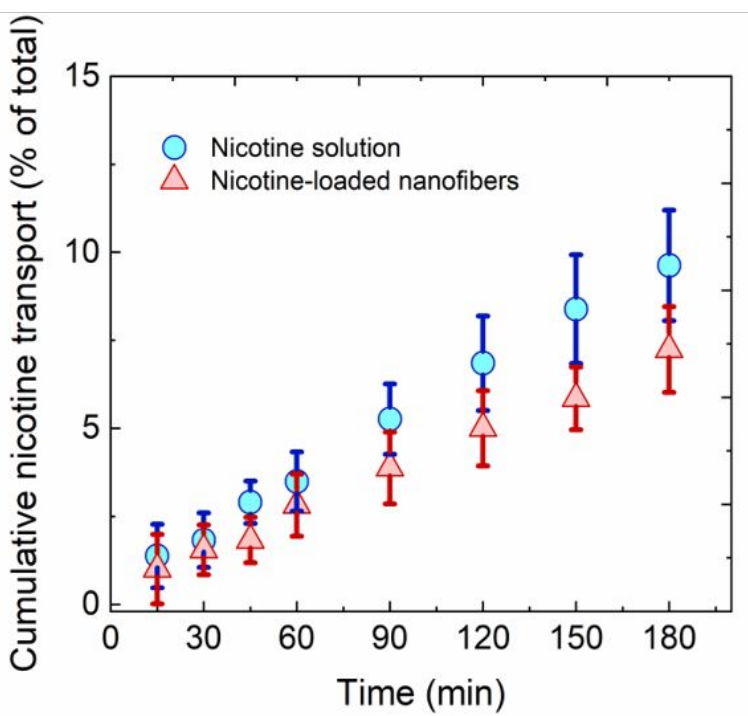

Figure 4: Nicotine transport across TR146 epithelium. (A) Cell viability (\%) of filter-cultured TR146 cells exposed to neat ALA/PEO nanofibers (ALA/PEO nanofibers), $0.3 \mathrm{mg} / \mathrm{mL}$ nicotine in hHBSS (Nicotine solution) or nicotine-loaded ALA/PEO nanofibers (Nicotine-loaded nanofibers) relative to control (hHBSS). (B) Nicotine transport ( $\%$ of total) from $0.3 \mathrm{mg} / \mathrm{mL}$ nicotine in hHBSS (Nicotine solution; $0.3 \mathrm{mg} / \mathrm{mL}$ equals to theoretical concentration of nicotine released from the nanofibers in hHBSS) and nanofiber disc with $0.225 \mathrm{mg}$ deposited nicotine (Nicotine-loaded nanofibers), from the apical to the basal cell side of filtercultured TR146 epithelium as a function of time during $3 \mathrm{~h}$ incubation. N=3,n=2-3, N representing the number of individual nanofiber mats prepared on separate days and individual cell passages, and $\mathrm{n}$ the number of samples from each replicate, results presented as the mean $\pm \mathrm{SD}$.

\section{Ex vivo permeation of nicotine through porcine buccal mucosa}

487 Permeation studies using ex vivo porcine buccal mucosa benefit from a relevant resemblance of

488 histology of the human buccal mucosa, and that the submucosa and lamina propria is included in 489 the barrier. ${ }^{50}$ For comparative reasons, ex vivo porcine mucosa was exposed to an amount of 490 nicotine in solution $10 \times$ higher than one dose provided by the nanofibers. Cumulative permeation

491 of nicotine across the ex vivo porcine buccal mucosa after exposure to the nicotine-loaded 492 ALA/PEO nanofibers or the solution of nicotine (Figure 5) resulted in flux values of 1.06 \pm 0.22 $493 \mathrm{nmol} /\left(\mathrm{cm}^{2} \times \min \right)(\mathrm{N}=3, \mathrm{n}=2-3 ;$ mean $\pm \mathrm{SD})$ and only $0.17 \pm 0.14 \mathrm{nmol} /\left(\mathrm{cm}^{2} \times \mathrm{min}\right)(\mathrm{N}=3, \mathrm{n}=3 ;$ mean $494 \pm \mathrm{SD}$ ), respectively. For nicotine in solution, the apparent permeability was thus $4.00 \pm 3.25 \times 10^{-8}$ $495 \mathrm{~cm} / \mathrm{s}(\mathrm{N}=3, \mathrm{n}=3$; mean $\pm \mathrm{SD})$. Previous studies conducted for nicotine permeability through ex vivo 496 porcine buccal mucosa with a thickness of $736 \pm 110 \mu \mathrm{m}(\mathrm{n}=4)$ reported apparent permeability 497 values of $1.44 \pm 0.49 \times 10^{-8} \mathrm{~cm} / \mathrm{s}$ and $1.54 \pm 0.12 \times 10^{-8} \mathrm{~cm} / \mathrm{s}$ for nicotine in solutions of different 
498 concentrations $\left(10^{-2} \mathrm{M}\right.$ and $10^{-3} \mathrm{M}$, respectively) and at $\mathrm{pH} \mathrm{7.4.7}$ Noteworthy, the permeation of 499 nicotine released from ALA/PEO nanofibers through ex vivo porcine buccal mucosa was not only 500 more efficient than of a highly concentrated nicotine solution $(10 \times$ the content of nicotine in the 501 nanofibers), but also significantly faster (Figure 5). This could be attributed to the fact that the 502 nicotine-loaded nanofibers were applied directly on the mucosa, providing fast nicotine release and 503 a site-specific high nicotine concentration gradient across the mucosal tissue driving passive 504 diffusion of nicotine into and through the buccal tissue.

505 Electrospun nanofibers have been employed to enable close contact between the epithelium of the 506 oral mucosa and the released drug, especially if unidirectional release is ensured. ${ }^{51}$ Backing layers, 507 which are usually of hydrophobic nature, direct the potential drug release towards the mucosa, 508 protect the releasing matrix against friction due to mechanical stress (movement of teeth and 509 tongue) and protect from wash-out of drug by saliva and thus maintaining the concentration 510 gradient for a prolonged time. ${ }^{52}$ To simulate this, close contact between the nanofibers and the 511 buccal mucosa and unidirectional release were assured during the ex vivo experiments. In general, 512 the permeability of nicotine was higher across TR146 epithelium compared to that through ex vivo 513 porcine buccal mucosa, which can mainly be explained by the increased thickness and higher 514 barrier properties of the porcine buccal mucosa compared to the TR146 cell culture model.

515

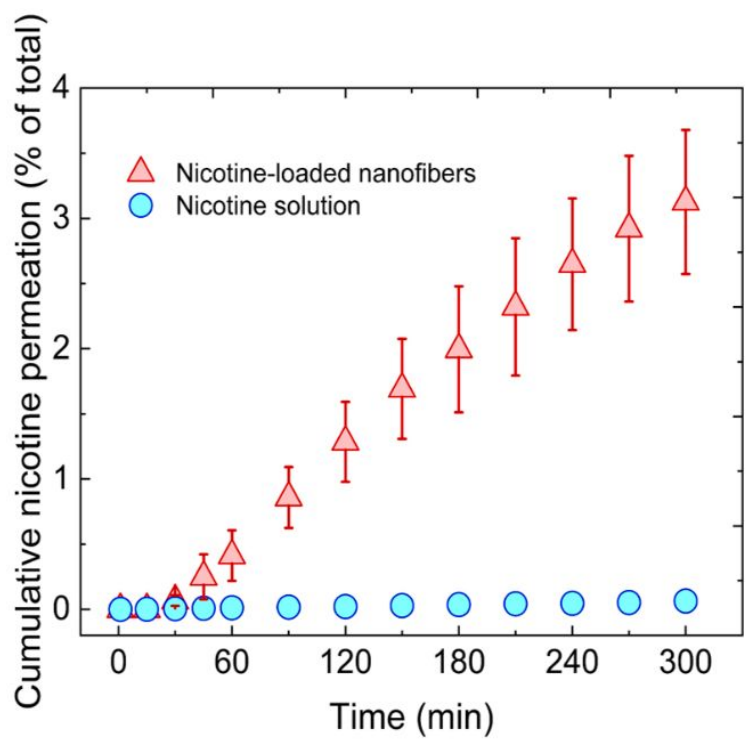

516 Figure 5: Permeation of nicotine through ex vivo porcine buccal mucosa. The permeated amount of nicotine (\% of dose) from 517 the donor compartment to the receptor compartment of the Ussing chambers given for ex vivo porcine buccal tissue exposed to 518 nicotine-loaded nanofibers (Nicotine-loaded nanofibers) and nicotine in PBS of $5.625 \mathrm{mg} / \mathrm{mL}$ (Nicotine solution) as a function of 
519 time during $5 \mathrm{~h}$ of incubation. $\mathrm{N}=3, \mathrm{n}=2-3, \mathrm{~N}$ representing the number of replications (individual nanofiber mats, tissue obtained 520 from individual pig), and $\mathrm{n}$ the number of individual samples tested. Results presented as mean \pm SD for nicotine-loaded nanofibers 521 and as mean values for nicotine solution. The SD bars for the nicotine solution are smaller than the symbol size.

\section{Nicotine delivered from nanofibers penetrated efficiently into ex vivo buccal mucosa}

523 MALDI MS imaging was conducted to assess the spatial distribution of nicotine into ex vivo 524 porcine buccal mucosa after topical application of the nicotine-loaded ALA/PEO nanofibers. In 525 Figure 6A, the spatial distribution of nicotine $(\mathrm{m} / \mathrm{z} 162.123)$ is visualized in red and the epithelium 526 is visualized in green by an endogenous molecule (sodium adduct of phosphatidylglycerol $527 \mathrm{PG}(34: 1), m / z$ 771.5131). The relative nicotine distribution in tissue was also visualized without 528 the epithelium biomarker (Figure 6B), using a color scale which provides a wider dynamic range 529 than what is possible in the overlaid image. Remarkably, nicotine penetrated throughout the entire 530 epithelium already within $1 \mathrm{~h}$ after the application of nicotine-loaded nanofibers on the ex vivo 531 porcine buccal mucosa. Signals of low intensities of nicotine can even be observed in the lamina 532 propria and the submucosa of the tissue, thus indicating penetration of nicotine also into these two 533 regions after $1 \mathrm{~h}$ of exposure. This is in accordance with results of the ex vivo permeation study, 534 which showed an approximate lag time of nicotine permeation through the ex vivo porcine mucosa 535 of $30 \mathrm{~min}$ (Figure 5). Moreover, the most intense detection of nicotine occurred at the site of 536 application of the nicotine-loaded nanofibers. H\&E staining was conducted post MALDI MS 537 imaging to evaluate the integrity of the tissue (Figure 6C). The tissue did not undergo visible 538 damage after cutting, preparation and, most importantly, after exposure to the nicotine-loaded 539 nanofibers for $1 \mathrm{~h}$ (Figure 6C). For comparison, MALDI MS imaging studies conducted by Marxen 540 et al. (Figure 6D) suggest that the main permeability barrier to nicotine is located in the epithelium, 541 since nicotine was not detectable further than the outer epithelial layers even after $3 \mathrm{~h}$ of apical 542 exposure to nicotine in solution $(61.6 \mathrm{mM}$ corresponding to $10 \mathrm{mg} / \mathrm{mL}) .{ }^{8}$ Overall, the permeation 543 studies and supporting imaging clearly underline the efficiency of the nicotine-loaded ALA/PEO 544 nanofibers as a fast-onset delivery system to facilitate the permeation of nicotine. The induced

545 higher nicotine tissue penetration by dosing the nicotine in nanofibers thus highlights the 546 importance of a tailored dosage form. 


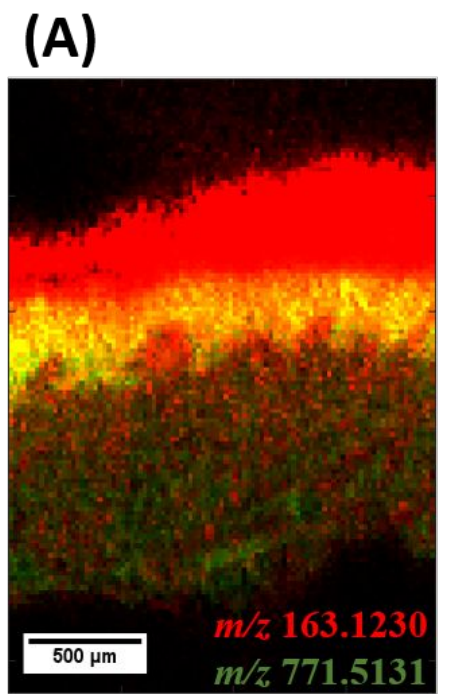

(B)

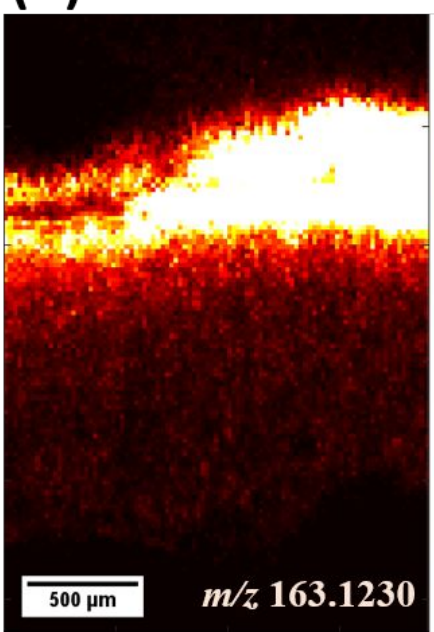

(C)

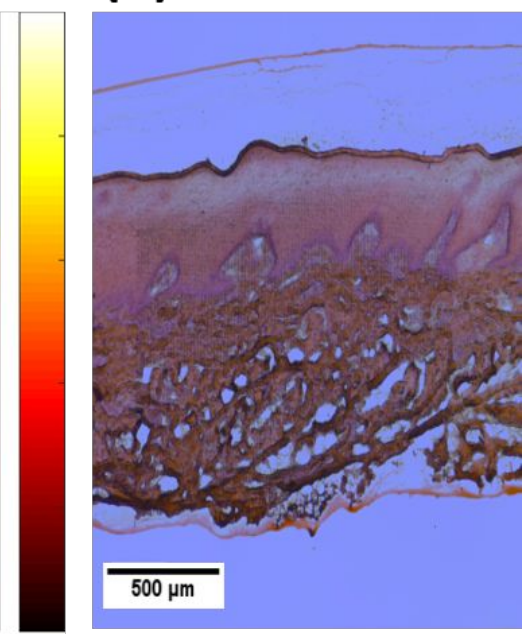

(D)
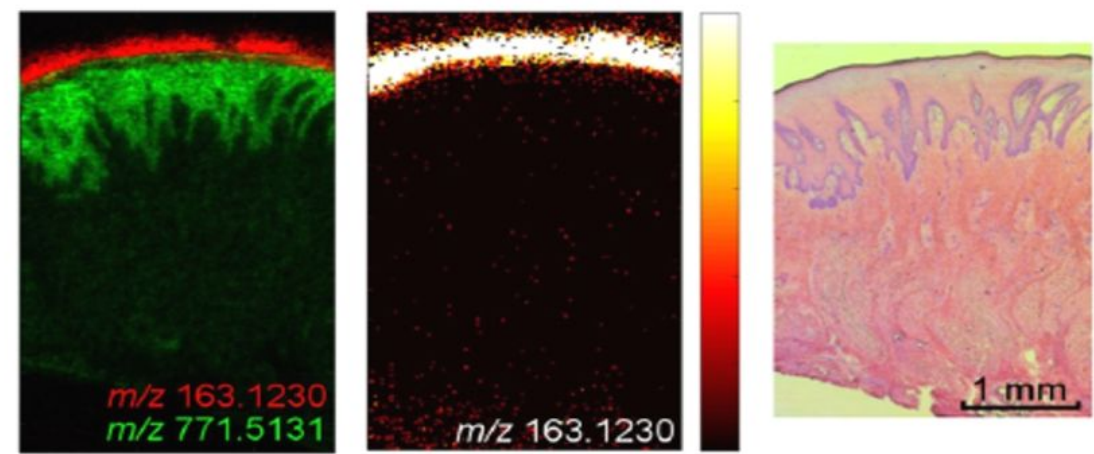

Figure 6: Representative images obtained by MALDI MS imaging of ex vivo porcine buccal mucosa exposed to nicotine-

550 loaded nanofibers for $1 \mathbf{h}$. (A) MALDI MS overlay image of nicotine (red) and an epithelium tissue marker (green). Red: Nicotine, $551 m / z 163.12297[\mathrm{M}+\mathrm{H}]^{+}$. Green: Epithelial marker PG (34:1), $m / z$ 771.5131 [M + Na $]^{+}$. Spatial resolution: $20 \mu \mathrm{m}$. (B) Distribution 552 of nicotine in ex vivo porcine buccal mucosa tissue, $\mathrm{m} / \mathrm{z} 163.12297[\mathrm{M}+\mathrm{H}]^{+}$. Spatial resolution: $20 \mu \mathrm{m}$. The intensity color scale 553 is shown next to the image. (C) H\&E stained ex vivo porcine buccal mucosa after MALDI MS imaging. $\mathrm{N}=2, \mathrm{~N}$ representing the 554 number of replicates (individual nanofiber mats and tissue obtained from individual pigs). (D) For comparison, MALDI MS and 555 HE stained images of a cross section of porcine buccal mucosa apically exposed to $70 \mu \mathrm{L}$ of $10 \mathrm{mg} / \mathrm{mL}$ nicotine in PBS for $3 \mathrm{~h}$. 556 Red: Nicotine, $\mathrm{m} / \mathrm{z} 163.1230[\mathrm{M}+\mathrm{H}]^{+}$. Green: Epithelial marker PG $(34: 1), \mathrm{m} / \mathrm{z} 771.5131[\mathrm{M}+\mathrm{Na}]^{+}$. Spatial resolution was 20 $557 \mu \mathrm{m}$. Adapted with permission from Marxen et al. ${ }^{8}$ Copyright (2018) American Chemical Society.

558 As previously reported, nicotine absorption across biological membranes is $\mathrm{pH}$-dependent and 559 nicotine penetrates the membranes faster in its unionized form. ${ }^{5}$ Thus, to improve the absorption 560 of nicotine, several of the existing NRT formulations, such as the nicotine chewing gum, are 561 buffered to alkaline $\mathrm{pH} .{ }^{5}$ Accordingly, the permeation of nicotine released from the nanofibers 
562 across buccal mucosa could potentially be further improved by the addition of buffering excipients 563 to the nanofibers. Further, ensuring closer tissue contact by introducing mucoadhesive properties 564 to the nicotine-loaded nanofibers, despite their fast disintegration, could enhance their effect. 565 Overall, the present results support that nicotine released from the ALA/PEO nanofibers efficiently 566 permeated the buccal absorption barrier. Their exceptional performance in promoting the mucosal 567 permeation of nicotine as well as their superiority to marketed NRT formulations in terms of 568 disintegration and nicotine release is expected to potentially satisfy cravings, omit throat soreness 569 and inhibit relapse more efficiently than the existing oromucosal NRT formulations. 


\section{CONCLUSION}

572 Nicotine was successfully loaded onto electrospun ALA/PEO nanofibers as a biocompatible drug 573 delivery system for buccal administration. The loaded amount of nicotine onto the nanofibers was 574 comparable to existing marketed oromucosal NRT formulations, namely a nicotine sublingual 575 tablet and lozenge. Nicotine-loaded nanofibers demonstrated fast disintegration in aqueous 576 medium and displayed the fastest release profile compared to two marketed NRT formulations for 577 oromucosal administration. Nicotine released from ALA/PEO nanofibers permeated more 578 efficiently through ex vivo porcine buccal tissue as compared to nicotine in solution. Increased 579 tissue penetration was also verified by MALDI MS imaging of the spatial distribution of nicotine 580 in ex vivo buccal tissue. Indeed, nicotine penetration into the epithelium, the lamina propria and 581 the submucosa of the buccal tissue was achieved when nicotine-loaded ALA/PEO nanofibers were 582 applied; this being an exceptional property of our drug delivery system. In conclusion, we show 583 that ALA/PEO nanofibers can act as a biocompatible, site-specific and fast-releasing drug delivery 584 system for nicotine and thus have potential to overcome the majority of drawbacks of already 585 existing NRTs.

\section{SUPPORTING INFORMATION}

587 The file contains details on the procedure for nicotine deposition on the nanofibers and fitting of 588 the release kinetics.

\section{ACKNOWLEDGEMENTS}

590 Authors acknowledge Davisco Food International/Agropur Ingredients (Eden Prairie, MN, USA) 591 for providing $\alpha$-lactalbumin. The Department of Experimental Medicine at the University of 592 Copenhagen is greatly acknowledged for providing the porcine tissue used for the ex vivo studies. 593 Charlotte Bagger is acknowledged for support with the MALDI-MS imaging studies and Lene 594 Grønne Pedersen for conducting the cell cultivation.

595 Funding: VF and KK acknowledge the VILLUM FONDEN for the Villum Young Investigator 596 Grant "Protein Superstructures as Smart Biomaterials (ProSmart)" 2018-2023 (project number: 597 19175). HMN, ISC, JJ, and MBS acknowledge The Danish Council for Independent Research; 598 Technology and Production (DFF-6111-00333). HMN, VF, KK, and MBS acknowledge support 599 from The Novo Nordisk Foundation for funding the Center for Biopharmaceuticals and Biobarriers 
600 in Drug Delivery (Grand Challenge Program; NNF16OC0021948). Further, the Support from the 601 Carlsberg Foundation and The Danish Council for Independent Research Medical Sciences (grant 602 no. DFF - 4002-00391) is gratefully acknowledged.

\section{AUTHORS CONTRIBUTION}

604 VF, HMN, JJ, MBS developed the idea behind the project. VF, HMN, JJ, MBS, KK, and CJ 605 designed the experiments. VF, HMN, JJ, CJ, and ISC provided the resources for the project. KK 606 and MBS performed the experiments and analyzed the data. KK wrote the original draft. MBS, CJ, 607 ISC, JJ, HMN, and VF reviewed and edited the manuscript. All authors approved the final version 608 of the manuscript.

609

610 DECLARATION OF INTERESTS

611 The authors declare no conflict of interest.

612

613 REFERENCES

614 1. World Health Organization. WHO Report on the global tobacco epidemic. Geneva, 2019. 615 https://apps.who.int/iris/bitstream/handle/10665/326043/9789241516204eng.pdf?ua=1 616 (accessed April 10, 2020).

617 2. U.S. National Cancer Institute and World Health Organization. The Economics of tobacco 618 and tobacco control; National Cancer Institute Tobacco Control Monograph 21, NIH 619 Publication No. 16-CA-8029A. Bethesda, MD: U.S. and Geneva, 2016; pp 65-99.

620 3. Cipolla D; Gonda I. Inhaled nicotine replacement therapy. Asian J Pharm Sci. 2015, 10 (6), $621 \quad 472-480$.

622 4. Vezina P; McGehee DS; Green WN. Exposure to nicotine and sensitization of nicotine623 induced behaviors. Prog Neuropsychopharmacol Biol Psychiatry 2007, 31 (8), 1625-1638.

624 5. Benowitz NL; Hukkanen J; Jacob P. Nicotine chemistry, metabolism, kinetics and 625 biomarkers. Handb Exp Pharmacol. 2009; 192, 29-60.

626 6. National Center for Biotechnology Information. PubChem Database. Nicotine, CID=89594. 627 https://pubchem.ncbi.nlm.nih.gov/compound/Nicotine (accessed April 10, 2020).

6287 Nielsen HM; Rømer Rassing M. Nicotine permeability across the buccal TR146 cell culture 629 model and porcine buccal mucosa in vitro: Effect of $\mathrm{pH}$ and concentration. Eur J Pharm Sci. $630 \quad$ 2002, 16, 151-157. 
631 8. Marxen E; Jacobsen J; Hyrup B; Janfelt C. Permeability barriers for nicotine and mannitol 632 in porcine buccal mucosa studied by high-resolution MALDI mass spectrometry imaging. 633 Mol Pharm. 2018, 15 (2), 519-526.

634 9. Prochaska JJ; Benowitz NL. The past, present, and future of nicotine addiction therapy. 635 Annu Rev Med. 2016, 67, 467-486.

636 10. Aubin HJ; Luquiens A; Berlin I. Pharmacotherapy for smoking cessation: pharmacological 637

11. Dale MM; Rang HP; Flower RJ; Ritter JM. In Rang and Dale's Pharmacology, $6^{\text {th }}$ ed.;

12. Hartmann-Boyce J; Chepkin SC; Ye W; Bullen C; Lancaster T. Nicotine replacement therapy versus control for smoking cessation. Cochrane Database Syst. Rev. 2018, 5 (5). https://doi:10.1002/14651858.CD000146.pub5.

13. West RJ. Psychology and pharmacology in cigarette withdrawal. J Psychosom Res. 1984, 28 (5), 379-386.

14. Mills EJ; Wu P; Lockhart I; Wilson K; Ebbert JO. Adverse events associated with nicotine replacement therapy (NRT) for smoking cessation. A systematic review and meta-analysis of one hundred and twenty studies involving 177,390 individuals. Tob Induc Dis. 2010, 8 (1). https://doi.org/10.1186/1617-9625-8-8.

15. Carpenter MJ; Jardin BF; Burris JL; Mathew AR; Schnoll RA; Rigotti NA, Cummings KM. Clinical strategies to enhance the efficacy of nicotine replacement therapy for smoking cessation: a review of the literature. Drugs. 2013, 73 (5), 407-426.

16. Le Houezec J. Role of nicotine pharmacokinetics in nicotine addiction and nicotine replacement therapy: A review. Int J Tuberc Lung Dis. 2003, 7 (9), 811-819.

17. Okeke OC; Boateng JS. Nicotine stabilization in composite sodium alginate based wafers and films for nicotine replacement therapy. Carbohydr Polym. 2017; 155, 78-88.

656

657

658

659

660

661

662

663

664

665

666

667

18. Boateng J; Okeke O. Evaluation of clay-functionalized wafers and films for nicotine replacement therapy via buccal mucosa. Pharmaceutics. 2019; 11 (3). https://doi.org/10.3390/pharmaceutics11030104.

19. Tiffany ST; Cox LS; Elash CA. Effects of transdermal nicotine patches on abstinenceinduced and cue-elicited craving in cigarette smokers. J Consult Clin Psychol. 2000, 68 (2), 233-240.

20. Bruce C; Manning M, inventor; Novartis Ag, assignee. Melt extruded nicotine thin strips. Google Patent WO2011081628A1. 2009 Dec 30.

21. Silagy C; Lancaster T; Stead L; Mant D; Fowler G. Nicotine replacement therapy for smoking cessation. Cochrane Database Syst Rev. 2004, 3. https://doi:10.1002/14651858.CD000146.pub2.

668 dependence. CA Cancer J Clin. 2005, 55 (5), 281-299. 
669 23. Khadka DB; Haynie DT. Protein- and peptide-based electrospun nanofibers in medical 670 biomaterials. Nanomedicine: Nanotechnology, Biology and Med. 2012, 8 (8), 1242-1262.

671 24. Babitha S; Rachita L; Karthikeyan K; Shoba E; Janani I; Poornima B; Sai P. Electrospun 672 protein nanofibers in healthcare: A review. Int J Pharm. 2017, 523, 52-90.

673 25. Sullivan ST; Tang C; Kennedy A; Talwar S; Khan SA. Electrospinning and heat treatment 674 of whey protein nanofibers. Food Hydrocoll. 2014, 35, 36-50.

675 26. Livney YD. Milk proteins as vehicles for bioactives. Curr Opin Colloid Interface Sci. 2010, $676 \quad 15(1-2), 73-83$.

677

678

679

680

681

682

683

684

685

686

687

688

689

690

691

692

693

694

695

696

697

698

699

700

27. Stie MB; Corezzi M; Bombin ADJ; Ajalloueian F; Attrill E; Pagliara S; Jacobsen J; Chronakis IS; Mørck Nielsen H; Foderà V. Waterborne electrospinning of alphalactalbumin generates tunable and biocompatible nanofibers for drug delivery. ACS Appl Nano Mater. 2020, 3 (2), 1910-1921.

28. Layman DK; Lönnerdal B; Fernstrom JD. Applications for $\alpha$-lactalbumin in human nutrition. Nutr Rev. 2018, 76 (6), 444-460.

29. Håkansson A; Svensson M; Mossberg AK; Sabharwal H; Linse S; Lazou I; Lönnerdal B; Svanborg C. A folding variant of a-lactalbumin with bactericidal activity against Streptococcus pneumoniae. Mol Microbiol. 2000, 35 (3), 589-600.

30. Rammer P; Groth-Pedersen L; Kirkegaard T; Daugaard M; Rytter A; Szyniarowski P; Høyer-Hansen M; Klitgaard Povlsen L; Nylandsted J; Larsen JE; Jäättelä M. BAMLET activates a lysosomal cell death program in cancer cells. Mol Cancer Ther. 20109 (1), 2432.

31. Korhonen H. Bioactive Milk Proteins, Peptides and Lipids and Other Functional Components Derived from Milk and Bovine Colostrum. In Functional Foods, $2^{\text {nd }}$ ed; Woodhead Publishing, 2011, pp 475-511.

32. Stie MB; Jones M; Sørensen HO; Jacobsen J; Chronakis IS; Mørck Nielsen H. Acids 'generally recognized as safe' affect morphology and biocompatibility of electrospun chitosan/polyethylene oxide nanofibers. Carbohydr Polym. 2019, 215, 253-262.

33. Mathematical models of drug release. In Strategies to modify the drug release from pharmaceutical systems.; Bruschi MLB Ed.; Woodhead Publishing, 2015; pp 63-86.

34. Zhang Y; Huo M; Zhou J; Zou A; Li W; Yao C; Xie S. DDSolver: an add-in program for modeling and comparison of drug dissolution profiles. AAPS J. 2010, 12 (3), 263-271.

701

702

703

704

705

706

707

35. Costa P; Sousa Lobo JM. Modeling and comparison of dissolution profiles. Eur J Pharm Sci. 2001, 13 (2), 123-133.

36. Marxen E; Axelsen MC; Pedersen AML; Jacobsen J. Effect of cryoprotectants for maintaining drug permeability barriers in porcine buccal mucosa. Int J Pharm. 2016, 511 (1), 599-605.

37. Robichaud G; Garrard KP; Barry JA; Muddiman DC. MSiReader: an open-source interface to view and analyze high resolving power MS imaging files on Matlab platform. J Am Soc Mass Spectrom. 2013, 24 (5), 718-721. 
708 38. Janfelt C; Wellner N; Leger P-L; Kokesch-Himmelreich J; Hansen SH; Charriaut-

709

710

711

712

713

714

715

716

717

718

719

720

721

722

723

724

725

726

727

728

729

730

731

732

733

734

735

736

737

738

739

740

741

742

743

744

745

746 Marlangue C; Hansen HS. Visualization by mass spectrometry of 2-dimensional changes in rat brain lipids, including $\mathrm{N}$-acylphosphatidylethanolamines, during neonatal brain ischemia. FASEB J. 2012, 26 (6), 2667-2673.

39. Santocildes-Romero ME; Hadley L; Clitherow KH; Hansen J; Murdoch C; Colley HE; Thornhill MH; Hatton PV. Fabrication of electrospun mucoadhesive membranes for therapeutic applications in oral medicine. ACS Appl Mater interfaces, 2017, 9 (13), 1155711567.

40. National Center for Biotechnology Information. PubChem Database. Bitartrate, $\mathrm{CID}=3667129$. https://pubchem.ncbi.nlm.nih.gov/compound/Bitartrate (accessed July 7, 2019).

41. Aframian D; Davidowitz T; Benoliel R. The distribution of oral mucosa $\mathrm{pH}$ values in healthy saliva secretors. Oral Dis. 2006, 12 (4), 420-423.

42. Torres-Martinez EJ; Cornejo Bravo JM; Serrano Medina A; Pérez González GL; Villarreal Gómez LJ. A summary of electrospun nanofibers as drug delivery system:drugs loaded and biopolymers used as matrices. Curr Drug Deliv. 2018, 15 (10), 1360-1374.

43. Um-i-Zahra S; Zhu L. Novel drug loaded duplicate nanofibers and their in vitro drug release profiles. Am Res Thoughts, 2015, 1 (6), 1683-1698.

44. Aguilar Z.Targeted drug delivery. In Nanomaterials for Medical Applications; Elsevier Inc. 2013; pp 181-234.

45. Li X; Kanjwal MA; Lin L; Chronakis IS. Electrospun polyvinyl-alcohol nanofibers as oral fast-dissolving delivery system of caffeine and riboflavin. Colloids Surfaces B Biointerfaces, 2013, 103, 182-188.

46. Caplan JL, inventor; Caplan JL, assignee. New therapeutic method of delivering a medicament to avoid irritating effects on membranes of users. International Patent WO2003077846A2. 2003 Sep 25.

47. Gajendran J; Kraemer J; Knudsen Randers S. Product performance test for medicated chewing gums. Dissolution Techn. 2008, 17 (3), 15-18.

48. Derakhshandeh K; Erfan M; Dadashzadeh S. Encapsulation of 9-nitrocamptothecin, a novel anticancer drug, in biodegradable nanoparticles: Factorial design, characterization and release kinetics. Eur J Pharm Biopharm., 2007, 66 (1), 34-41.

49. Marxen E; Mosgaard MD; Pedersen AML; Jacobsen J. Mucin dispersions as a model for the oromucosal mucus layer in in vitro and ex vivo buccal permeability studies of small molecules. Eur J Pharm Biopharm. 2017, 121, 121-128.

50. Pinto S; Pintado ME; Sarmento B. In vivo, ex vivo and in vitro assessment of buccal permeation of drugs from delivery systems. Expert Opin Drug Deliv. 2020, 17 (1), 33-48.

51. Colley HE; Said Z; Santocildes-Romero ME; Baker SR; Apice KD; Hansen J; Siim Madsen L; Thornhill MH; Hatton PV; Murdoch C. Pre-clinical evaluation of novel mucoadhesive bilayer patches for local delivery of clobetasol-17-propionate to the oral mucosa. 
1

2

747

748

749

750

751

752

\section{GRAPHICAL ABSTRACT}

16

17

18

19

20

21

22

23

24

25

26

27

28

29

30

31

32

33

34

35

36

37

38

39

40

41

42

43

44

45

46

47

48

49

50

51

52

53

54

55

56

57

58

59

60 385-403.

Biomaterials, 2018, 178, 134-146.

52. Chinna Reddy P; Chaitanya KS; Madhusudan Rao Y. A review of bioadhesive buccal drug delivery systems: current status of formulation and evaluation methods. Daru, 2011, 19 (6),

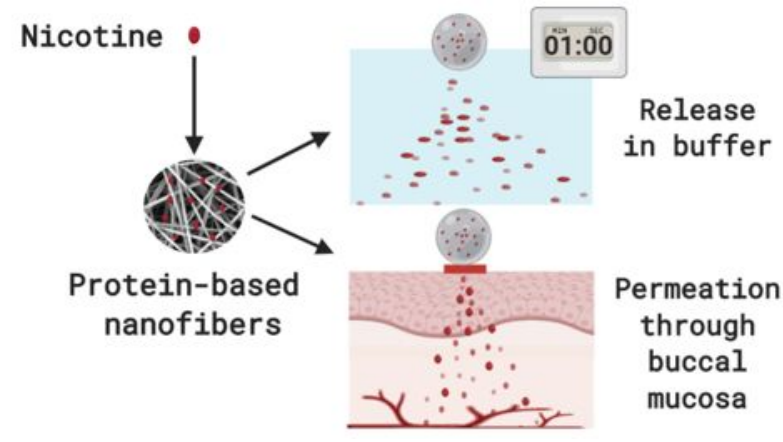

755 Graphical abstract for "Electrospun $\alpha$-lactalbumin nanofibers for site-specific and fast-onset delivery of nicotine in the oral cavity:

756 an in vitro, ex vivo and tissue spatial distribution study." Created with BioRender.com. 